Music therapy enhances executive functions and prefrontal structural neuroplasticity after traumatic brain injury : Evidence from a randomized controlled trial

\title{
Siponkoski, Sini-Tuuli
}

2020-02-15

Siponkoski , S-T , Martinez Molina , N , Kuusela , L , Laitinen , S , Holma , M , Ahlfors , M , Jordan-Kilkki , P , Ala-Kauhaluoma , K, Melkas , S, Pekkola , J , Rodriguez-Fornells , A , Laine , M , Ylinen, A , Rantanen , P , Koskinen , S , Lipsanen , J \& Särkämö , T 2020 , ' Music therapy enhances executive functions and prefrontal structural neuroplasticity after traumatic brain injury : Evidence from a randomized controlled trial ' , Journal of Neurotrauma , vol. 37 , no. 4 , pp. 618-634 . https://doi.org/10.1089/neu.2019.6413

http://hdl.handle.net/10138/328411

https://doi.org/10.1089/neu.2019.6413

unspecified

acceptedVersion

Downloaded from Helda, University of Helsinki institutional repository.

This is an electronic reprint of the original article.

This reprint may differ from the original in pagination and typographic detail.

Please cite the original version. 


\section{Music Therapy Enhances Executive Functions and Prefrontal \\ Structural Neuroplasticity after Traumatic Brain Injury: Evidence from a Randomized Controlled Trial}

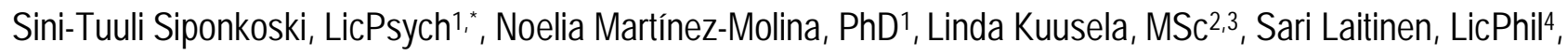
Milla Holma, MA5, Mirja Ahlfors, MA, Päivi Jordan-Kilkki ${ }^{6}$, MM, Katja Ala-Kauhaluoma, LicPsych7, Susanna Melkas, MD, PhD², Johanna Pekkola, MD, PhD², Antoni Rodriguez-Fornells, PhD'-11, Matti Laine, PhD'12, Aarne Ylinen, MD, PhD13,8, Pekka Rantanen, MD, PhD14, Sanna Koskinen, PhD15, Jari Lipsanen, PhD15, Teppo Särkämö, PhD1

${ }^{1}$ Cognitive Brain Research Unit, Department of Psychology and Logopedics, University of Helsinki, Finland ${ }^{2}$ HUS Medical Imaging Center, Department of Radiology, Helsinki Central University Hospital and University of Helsinki, Finland

${ }^{3}$ Department of Physics, University of Helsinki, Finland

${ }^{4}$ Espoo hospital, Finland

${ }^{5}$ Musiikkiterapiaosuuskunta InstruMental (music therapy cooperative InstruMental), Finland

${ }^{6}$ Dialogic Partner Oy, Espoo, Finland

${ }^{7}$ Ludus Oy Tutkimus- ja kuntoutuspalvelut (Assessment and intervention services), Helsinki, Finland

${ }^{8}$ Department of Neurology \& Brain Injury Outpatient Clinic, Helsinki University Central Hospital, Finland

${ }^{9}$ Cognition and Brain Plasticity Group, Bellvitge Biomedical Research Institute, L'Hospitalet de Llobregat, Barcelona, Spain

10Department of Cognition, Development and Educational Psychology, University of Barcelona, Spain ${ }^{11}$ Catalan Institution for Research and Advanced Studies, Barcelona, Spain

${ }^{12}$ Department of Psychology, Åbo Akademi University, Turku, Finland

${ }^{13}$ Tampere University Hospital, Finland

${ }^{14 K a n t a-H a ̈ m e ~ C e n t r a l ~ H o s p i t a l, ~ H a ̈ m e e n l i n n a, ~ F i n l a n d ~}$

${ }^{15}$ Department of Psychology and Logopedics, University of Helsinki, Finland

*Corresponding author (contact: sini-tuuli.siponkoski@helsinki.fi)

Running title:

Music Therapy Aids Cognitive Recovery in TBI (44/45 characters)

Table of Contents title:

Music Therapy Enhances Cognitive Recovery and Neuroplasticity after TBI (71/75 characters)

Keywords:

Traumatic brain injury, music therapy, randomized controlled study, executive function, voxel-based morphometry 


\section{Contact information}

Sini-Tuuli Siponkoski, Cognitive Brain Research Unit, Department of Psychology and Logopedics, University of Helsinki, Haartmaninkatu 3, room F212, P.O. Box 21, Fl-00014 University of Helsinki, Finland; phone +358 4453626 98; e-mail sini-tuuli.siponkoski@helsinki.fi

Noelia Martinez-Molina, Cognitive Brain Research Unit, Department of Psychology and Logopedics, University of Helsinki, Haartmaninkatu 3, room F212, P.O. Box 21, FI-00014 University of Helsinki, Finland; phone +358 5031880 48; e-mail noelia.martinezmolina@helsinki.fi

Linda Kuusela, HUS Helsinki Medical Imaging Center, Radiology, POB 340, 00029 HUS; phone +358 50482 6825; email. linda.kuusela@hus.fi

Sari Laitinen, Espoo hospital, P.O.B. 2550, 02070 Espoo city, phone +358 50 3377466; e-mail sari@kadenssi.fi

Milla Holma, Korpisola 3C 02300 Espoo; phone +358 40730 5525; e-mail milla.holma@elisanet.fi

Mirja Ahlfors, Vanha Saunalahdentie 14 C 10, 02330 Espoo; phone +358 405894900; e-mail mirja.ahlfors@kolumbus.fi

Päivi Jordan-Kilkki, Kivenhakkaajantie 12 A, 04200 Kerava, Finland; phone +358414559319; e-mail paivi@jordan-kilkki.fi

Katja Ala-Kauhaluoma, Ludus Oy Tutkimus- ja kuntoutuspalveut, Mäkitorpantie 3 B, 00620 Helsinki, Finland; phone +358 40 1326697; e-mail katja.ala-kauhaluoma@ludus.fi

Susanna Melkas, Department of Neurology \& Brain Injury Outpatient Clinic, Helsinki University Hospital. Paciuksenkatu 21, 00029 HUS (Helsinki); phone +358 40501 3589; e-mail susanna.melkas@hus.fi Johanna Pekkola, Alitilantie 9A, 01800 Klaukkala; phone +35850 3083672; e-mail johanna.pekkola@hus.fi Antoni Rodriguez-Fornells, Cognition and Brain Plasticity Unit (CBPU), ICREA \& Dept. of Cognition, Development and Education Psychology \& IDIBELL (Campus de Bellvitge). University of Barcelona. Feixa Llarga s/n, 08907, L'Hospitalet (Barcelona), Spain; Phone: +34 934021038; e-mail Antoni.rodriguez@icrea.cat Matti Laine, Department of Psychology, Åbo Akademi University, Fabriksgatan 2, 20500 Turku, Finland; phone +358-469219168; e-mail matti.laine@abo.fi

Aarne Ylinen Tampere University Hospital, Sastamala, 38200 Sastamala, Finland; phone +358 50 3006660; email aarne.ylinen@pshp.fi

Pekka Rantanen, Kanta-Häme Central Hospital, 13530 Hämeenlinna; phone +3583 629 2040; e-mail pekka.rantanen@khshp.fi

Sanna Koskinen, Department of Psychology and Logopedics, University of Helsinki, Haartmaninkatu 3, P.O.Box 21, FI-00014 University of Helsinki, Finland; phone +358 50 5410146; e-mail sanna.koskinen@helsinki.fi

Jari Lipsanen, Department of Psychology and Logopedics, University of Helsinki, Haartmaninkatu 3, P.O.Box 21, FI-00014 University of Helsinki, Finland; phone +358294129446; email jari.lipsanen@helsinki.fi

Teppo Särkämö, Cognitive Brain Research Unit, Department of Psychology and Logopedics, University of Helsinki, Haartmaninkatu 3, room F108, P.O. Box 21, FI-00014 University of Helsinki, Finland; phone: +358 50 5399 065; e-mail teppo.sarkamo@helsinki.fi 


\begin{abstract}
Traumatic brain injury (TBI) causes lifelong cognitive deficits, particularly impairments of executive functioning (EF). Musical training and music-based rehabilitation have been shown to enhance cognitive functioning and neuroplasticity, but the potential rehabilitative effects of music in TBI are still largely unknown. The aim of the present cross-over randomized controlled trial (RCT) was to determine the clinical efficacy of music therapy on cognitive functioning in $\mathrm{TBI}$ and to explore its neural basis. Using an $\mathrm{AB} / \mathrm{BA}$ design, 40 patients with moderate or severe TBI were randomized to receive a 3-month neurological music therapy intervention either during the first $(A B, n=20)$ or second $(B A, n=20)$ half of a 6 -month follow-up period. Neuropsychological and motor testing and MRI scanning was performed at baseline and at the 3-month and 6-month stage. 39 subjects who participated in baseline measurement were included in an intention-to-treat analysis using multiple imputation. Results showed that general EF (as indicated by the Frontal Assessment Battery) and set shifting improved more in the $A B$ group than in the BA group over the first 3-month period and the effect on general EF was maintained in the 6-month follow-up. Voxel-based morphometry (VBM) analysis of the structural MRI data indicated that grey matter volume (GMV) in the right inferior frontal gyrus (IFG) increased significantly in both groups during the intervention vs. control period, which also correlated with cognitive improvement in set shifting. These findings suggest that neurological music therapy enhances EF and induces fine-grained neuroanatomical changes in prefrontal areas.
\end{abstract}

(248/250 words)

Keywords: music therapy, traumatic brain injury, executive function, voxel-based morphometry 


\section{INTRODUCTION}

Traumatic brain injury (TBI) is a major cause of disability across all ages. Over 50 million people have TBI each year worldwide. ${ }^{1}$ Injury often changes the life of the patients in a very profound way, with the effects extending from physical injury and fatigue to cognitive, emotional, and behavioural impairments..$^{2-5}$ Cognitive impairments vary across patients, depending on injury severity and location, but most deficits are in the domains of attention, memory, communication, and executive functioning (EF) ${ }^{1,6-9} \mathrm{EF}$ is a broad term referring to "high-level" cognitive processes that enable individuals to regulate their thoughts and actions during goal-directed behaviour. ${ }^{10}$ There is no consensus on the exact definition of the term, but various cognitive processes such as set shifting (switching from one task to another), inhibition (avoiding a dominant or prepotent response), and updating (continuously updating the contents of working memory) have been proposed as key components of EF. ${ }^{10}$ Importantly, deficits in EF are considered to be the core symptoms of $\mathrm{TBI}$, affecting the everyday life and coping of the patients as well as posing major challenges for rehabilitation. 11, 12

Given the substantial burden caused by TBI on individual survivors, their families, and the whole society, new effective rehabilitation methods are urgently needed. Considering the heterogeneous and complex nature of $\mathrm{TBI}$, there is a need especially for motivating rehabilitation tools that are able to address multiple deficits simultaneously, especially targeting executive skills. Behavioural and neuroimaging studies in healthy individuals have revealed that musical training enhances EF and the recruitment of the cognitive control network, raising the question of whether music-based interventions could have similar positive effects on the executive dysfunction experienced by TBI patients. ${ }^{13-22}$ Considering also that the ability to enjoy and engage in musical activities is typically well preserved after brain injury, ${ }^{23}$ music offers a very promising, novel approach to neurorehabilitation after TBI. Music-based interventions have been shown to enhance verbal memory, focused attention, and visual awareness as well as to improve mood and quality of life in stroke patients. ${ }^{24-27}$ Further, music strongly engages the brain's reward system which can be important concerning the problems of initiation and motivation often linked to TBI. ${ }^{28-31} \mathrm{~A}$ recent randomized controlled trial in acute stroke patients revealed that the impact of Music-Supported Training (MST) on motor functions was larger in patients who experienced music particularly rewarding, pointing to the involvement of motivation and reward circuits in the effectivity of music-based interventions. ${ }^{32}$ Moreover, music aids in regulating arousal and vigilance, ${ }^{33,34}$ which can be particularly helpful for TBI patients as fatigue is highly common after TBI. Music has also the potential to support motor functions in neurological disorders. Learning and playing-based music interventions, such as MST, have been shown to enhance fine and gross motor skills and also promote auditory and motor neuroplasticity in chronic stroke patients. ${ }^{35-39}$ Collectively, this evidence suggests that music therapy holds much potential in the rehabilitation of cognitive, motor, and emotional deficits after TBI in a rich, motivating, and versatile way. 
Accumulating evidence is supporting the view that the initial injury caused by TBI can be followed over time by loss of brain volume (atrophy), which reflects the clearance of dysfunctional tissue. This brain atrophy can be quantified using volumetric MRI measures and has been associated with diffuse axonal injury (DAI). ${ }^{40}$ Many neuroimaging studies using voxel-based morphometry (VBM) have reported a progressive loss of brain volume after TBI. ${ }^{7}, 41-43$ In the chronic phase, the regions with grey matter volume (GMV) reductions included the frontal, temporal, occipital, and insular cortices, whereas white matter volume (WMV) loss was observed in the corpus callosum, corona radiata, internal capsule, and brainstem. ${ }^{44}$ The link between cognitive performance and brain volume is not straightforward, and the observed cognitive trajectory after TBI is complex, with both patterns of improvement and detoriation. ${ }^{45-47}$ Importantly, it has been suggested that the post-TBI behavioural and neural changes could be mediated by post-injury environmental factors, with cognitive disuse and environmental impoverishment contributing to poor recovery and negative neuroplasticity changes and environmental enrichment contributing to better recovery and positive neuroplasticity changes. ${ }^{48-}$ 50 It can therefore be hypothesized that the observed progressive brain volume loss could be modified by the structural neuroplastic changes induced by music-based interventions. In support of this idea, a recent VBM study in our laboratory revealed GMV increases in a network of prefrontal and limbic areas in left hemisphere stroke patients after a music listening intervention. ${ }^{26}$ The GM reorganization in prefrontal areas correlated with enhanced recovery of high-level cognitive functions including verbal memory, focused attention, and language skills, suggesting that volumetric changes in these regions may serve as clinical biomarkers of music therapy efficacy also after TBI.

To date, very little research has, however, been conducted on the effectiveness of music-based interventions after TBI, especially using controlled experimental paradigms. Previous studies have revealed some positive effects of music on emotional well-being and social functioning in TBI patients. ${ }^{51-54} \mathrm{It}$ is noteworthy that music can also offer a route for enhancing arousal and awareness and improving behavioural outcome in those severe TBI patients with a disorder of consciousness, such as coma. ${ }^{55,56}$ Later in the rehabilitation process, singing can be helpful in facilitating speech production as well as providing a psychological tool for exploring self-concept after injury. ${ }^{57-60}$ When used in gait rehabilitation of TBI, rhythm of music has also been observed to improve motor coordination. ${ }^{61,62}$

Thus far, only few studies have explored the cognitive effects of the music-based interventions after TBI. In a quasi-experimental study, Thaut et al. (2009) gave four 30-minute sessions of neurological music therapy to brain injury patients $(n=31)$ and conducted pre-post assessments for each session. ${ }^{63}$ Compared to a patient control group $(n=23)$ who performed the same assessments twice but did not receive any intervention, the intervention group improved in EF (mental flexibility) after a single session, coupled with positive effects on self-reported mood and self-efficacy. ${ }^{63}$ More recently, Lynch and LaGlasse (2016) conducted a small-scale feasibility study evaluating the effect of five sessions of Musical Executive Function Training (MEFT) on EF in 
brain injury patients. ${ }^{64}$ The patients $(n=14)$ were randomly assigned to a MEFT group, singing group, and control group. No significant intervention effects were observed, although the MEFT group showed a trend towards an enhancement of mental flexibility. ${ }^{64}$ Very recently, Vik et al. (2018) gave patients with mild TBI $(n=$ 7) eight weeks of active piano training (tuition twice per week plus home training) and compared them to healthy subjects who either received the same piano training $(n=11)$ or did not receive any intervention $(n=$ 12). ${ }^{65}$ The piano training groups (both TBI patients and healthy subjects) improved on verbal learning performance and the TBI group also showed increased activation in the right orbitofrontal cortex in a music listening task. ${ }^{65}$

In summary, the three studies listed above provide preliminary evidence that music-based rehabilitation can have cognitive benefits after brain injury. ${ }^{63-65}$ However, regarding the clinical efficacy of music-based rehabilitation, the conclusions that can be drawn from these studies are limited by the small sample sizes, lack of proper randomized controlled trial (RCT) designs, and, in the case of two studies, the use of mixed brain injury samples (inclusion of patients with an injury mechanism other than TBI). Also the outcome measures used in the studies were very brief and did not cover different domains on EF and attention systematically. Therefore, larger and more detailed RCTs in TBI patients are needed.

In the current study, we addressed this knowledge gap by performing a single-blinded and cross-over RCT to investigate the effectiveness of neurological music therapy in TBI patients. We introduced a novel form of neurological music therapy specifically designed to meet the rehabilitation needs of TBI patients, targeting deficits in EF, attention, and working memory as well as motor skills and emotional adjustment. Importantly, the intervention required no previous musical experience, and it was adaptable to different types of TBI patients regarding the level of injury. We hypothesized that the intervention would be especially effective in the rehabilitation of EF, which was defined as the primary outcome of the study. In addition, we also carried out a volumetric analysis using VBM on structural MRI scans to examine the potential neuroprotective effect of the music therapy after TBI. Based on the previous literature, we hypothesized that the music therapy would induce structural neuroplastic changes, especially in prefrontal brain regions that have been associated with attention, memory, and EF. 


\section{METHODS}

\section{Subjects and study design}

Forty TBI patients from the Helsinki and Uusimaa area were recruited through the Brain Injury Clinic of the Helsinki University Central Hospital (HUCH), Validia Rehabilitation Helsinki, and the Department of Neurology of Lohja hospital during 2014-2017 to this RCT (trial number: NCT01956136). The inclusion criteria were: 1) diagnosed (ICD-10) TBI fulfilling the criteria of at least moderate severity (Glasgow Coma Scale: $\leq 12 \mathrm{p}$ and/or posttraumatic amnesia (PTA) $\geq 24$ hours);66 2) time since injury $\leq 24$ months at the time of recruitment; 3 ) cognitive symptoms caused by TBI (attention, executive function, memory); 4) no previous neurological or severe psychiatric illnesses or substance abuse; 5) age 16-60 years; 6) native Finnish speaking or bilingual with sufficient communication skills in Finnish; 7) living in the Helsinki-Uusimaa area; and; 8) understanding the purpose of the study and being able to give an informed consent. No power analysis was conducted due to the exploratory nature of the study; there are no previous studies on similar music interventions in this particular patient population that would provide a reliable reference for effect size evaluations. Our sample size target $(n=40)$ was set in order to gather a representative sample within a reasonable time window. The trial was conducted according to the Declaration of Helsinki and was consistent with good clinical practice and the applicable regulatory requirements. The trial protocol was approved by the Coordinating Ethics Committee of the Hospital District of Helsinki and Uusimaa (reference number 338/13/03/00/2012) and all participants signed an informed consent.

The study was a cross-over RCT with a 6-month follow-up period. Upon recruitment, subjects were randomly assigned to one of two groups, $A B(n=20)$ and $B A(n=20)$. Randomization was performed using an online random number generator (https://www.random.org/) by a person not involved in patient recruitment or assessments. To ensure steady allocation to both groups across the trial, the randomization was done in batches of two consecutive patients. The randomization was stratified for lesion laterality (left / right / bilateral). During the first three months, the $A B$ group received neurological music therapy in addition to standard care whereas the BA group received only standard care. During the second 3-month period, the BA group received the music therapy intervention and standard care and the $A B$ group received only standard care. Baseline measurements were administered at time point 1 (TP1) and follow-up measurements were conducted at the 3month cross-over point (TP2) and at the 6-month completion point (TP3). The research personnel conducting the behavioural tests and MRI scans was blinded regarding the group allocation of the participants. The subjects and their caregivers were informed about the blinding procedure and were instructed to discuss therapy-related issues only with the music therapists. 
The flow chart of the included TBI patients is shown in Figure 1. During 2014-2017, 4994 TBI patients were screened for eligibility, 190 met the inclusion criteria, and 40 were randomized to the $A B$ and $B A$ groups. Of these, one participant dropped out before the baseline measurements, two participants dropped out before TP2 and another three participants dropped out before TP3. The drop-outs were mainly due to lack of energy and motivation. All of the drop-outs $(n=6)$ occurred in the BA group which was likely linked to the long waiting period before the intervention. Of these, only one occurred during the music therapy intervention, the remaining five took place before the onset of the intervention. Compared to the rest of the BA group, the subjects who dropped out had lower education level, longer posttraumatic amnesia, and worse injury outcome according to GOSE. MRI was not possible to perform in 8 participants due to contraindications or technical difficulties during the scanning. Detailed information concerning the subjects' demographic and clinical data and musical experience is presented in Table 1.

\section{Intervention}

The neurological music therapy intervention was targeted primarily for the (i) rehabilitation of cognitive deficits, especially of executive function, attention, and working memory, with a secondary goal of enhancing (ii) mood and emotional adjustment and (iii) upper extremity motor functions. The intervention model was adapted from two existing music therapy methods: Functionally-Oriented Music Therapy (FMT) (https://www.fmt-

metoden.se/fmtsiteng/index.html) and Music-Supported Training (MST) method, which have both been applied in stroke rehabilitation. ${ }^{36,38,67}$ Importantly, the intervention required no previous musical experience and was adaptable to different types of TBI patients depending on the level of injury.

The intervention consisted of 20 individual therapy sessions (2 times/week, $60 \mathrm{~min} / \mathrm{session}$ ) held by a trained music therapist (authors S.L., M.H., and M.A.) at Validia Rehabilitation Helsinki and focusing on active musical production with different instruments (drums, piano). Each session included three modules (20 min each): (i) rhythmical training, (ii) structured cognitive-motor training, and (iii) assisted music playing. Rhythmical training involved playing sequences of musical rhythms and coordinated bimanual movements on a djembe drum and on own body. Structured cognitive-motor training involved playing musical exercises on a drum set with varying levels of movement elements and composition of drum pads, accompanied by the therapist with piano. Assisted music playing comprised of learning to play the participant's own favorite songs on the piano with the help of the therapist and using Figure Notes (https://www.figurenotes.org/what-is-figurenotes/), a special musical notation system utilizing colors and shapes originally developed in Finland, which makes music playing easily accessible without prior musical education.

Importantly, in all the modules, the difficulty level of the exercises was initially adjusted and increased in a step-wise manner within and across the sessions to meet the skill level and progression of the individual 
participant. In addition, musical improvisation was included in all modules and encouraged throughout the therapy to facilitate creative expression. All in all, the training performed during the intervention tapped into a number of executive (action planning and monitoring, inhibitory control, shifting), attentional (focused attention, spatial attention, vigilance), and working memory (updating) as well as motor (motor control, eye-movement coordination) and emotional (affect regulation, emotional expression) functions.

\section{Behavioural outcome measures}

During the recruiting process, both the Glasgow Coma Scale Extended (GOSE) and the Neurological Outcome Scale for Traumatic Brain Injury (NOS-TBI) were administered in order to obtain information of the overall symptoms and current functional outcome after TBI. ${ }^{68,69}$ The effects of the intervention were evaluated by using neuropsychological and motor test batteries and structural MRI, administered at three time points (TP1, TP2, and TP3). The neuropsychological assessments were conducted by a licensed psychologist (authors S-T.S. and K.A-K.) and each testing session lasted approximately 2 hours. Motor testing was performed by a physiotherapist / occupational therapist and it took approximately 45 minutes. All behavioural testing sessions took place at Validia Rehabilitation Helsinki in a quiet test room. The participants had the opportunity to take a short break during the sessions if needed. In the study protocol, also questionnaire data mapping functional outcome, emotional adjustment, and quality of life of the patients and their caregivers were collected. Results from this data will be later reported elsewhere. However, the baseline score of the Beck Depression Inventory II (BDI-II) will be included in this study as background information on the level of depression. ${ }^{70}$

Primary outcome measure. The primary outcome measure was change in performance on the Frontal Assessment Battery (FAB). ${ }^{71}$ FAB measures different aspects of frontal lobe functions. It consists of six subtests exploring conceptualization (similarities subtest), mental flexibility (lexical fluency), motor programming (Luria's fist-edge-palm test), sensitivity to interference (conflicting instructions), inhibitory control (go-no go task), and environmental autonomy (prehension behaviour). FAB has previously been shown to be sensitive to TBI-related cognitive changes and it has a good test-retest reliability. ${ }^{72,73}$ The FAB total score (percentage correct) formed the composite score of EF, as the measure is designed to assess global EF and it is applicable through various severity levels of TBI

Secondary outcome measures. Other cognitive and motor tests were defined as secondary outcome measures. Cognitive tests included computerized tests of EF and sustained attention, as well as measures of reasoning and verbal memory. Parallel versions of memory tests were used in different time points to minimize practice effects. The computerized tests of EF were chosen to reflect different aspects of EF (set shifting, updating, inhibition) defined by Miyake et al. (2000)..$^{74}$ They were regarded as secondary measures since they 
reflect more narrow aspects of EF compared to the FAB. Motor tests were used to evaluate fine and gross motor functioning, dexterity, and coordination of the upper limbs.

Set shifting was assessed by the Number-Letter Task (NLT). ${ }^{75}$ In this computerized test, a number-letter combination appeared in one of two squares (top/bottom) in the centre of the screen and the subject was instructed to make a decision either based on the number or the letter by pressing one of two buttons. The task was divided into three blocks, each preceded by a short practice phase. In the first block (32 trials), all of the stimuli appeared in the top box and the task was to determine whether the number was odd or even. In the second block (32 trials), all of the stimuli appeared in the bottom box and the task was to determine whether the letter was a vowel or a consonant. In the third block, the stimuli randomly appeared in either of the squares, and the subject had to respond accordingly (make a decision based on the number if in the top square and based on the letter if in the bottom square). The third block had 32 switch trials (target different from the previous trial) and 48 non-switch trials (target same as in the previous trial). Switching costs for both reaction times and error percentages were calculated by comparing performance on switching and nonswitching trials in the third block. ${ }^{75}$

Updating was assessed by using a computerized Auditory N-back Task. ${ }^{76}$ The stimuli in this task consisted of three chords varying in their pitch (low/medium/high). The task was to determine if the stimulus was same/different compared to the previous stimulus (1-back) or the stimulus before that (2-back) by pressing one of two buttons. The task was divided into 4 blocks of 25 trials (two 1-back blocks and two 2-back blocks). The 1-back blocks were presented first, followed by the 2-back blocks. A short practice phase preceded both conditions.

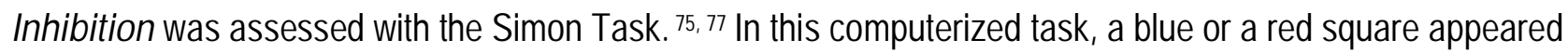
either on the left or the right side of the screen. The instruction was to press the right button each time a red square appeared and the left button each time a blue square appeared, irrespective of which side the square was presented on. On congruent trials, the response button was on the same side as the square; on incongruent trials, it was on the opposite side. There were 100 trials (50 congruent, 50 incongruent). Simon effect was calculated by comparing congruent and incongruent trials, reflecting the cost of irrelevant spatial information on reaction time and number of errors. A short practice phase preceded the task.

Sustained attention was assessed by using the Sustained Attention to Response Task (SART). ${ }^{78}$ In this computerized task, digits ranging from 1 to 9 are presented on a screen in a random order. Each digit was presented for 149 ms, followed by a 900-ms mask. The task was to respond to every other digit except digit "3" by pressing a response button. The original SART task consists of 225 digits, of which 25 digits are targets (3). For the purpose of this study, we created a version of the test with 450 digits including 50 targets (length approximately $8.6 \mathrm{~min}$ ), in order to better detect TBI-related problems of sustaining attention over a long period 
of time. A short practice phase preceded the task. Both omissions and commissions in the SART were included in the analysis, since together they provide a more complete picture on the performance, reflecting inhibition errors as well as lapses of attention. ${ }^{79}$ We also analyzed vigilance decrement during the task by comparing error rates and reaction times during the first and second halves of the task. ${ }^{80}$

For the other secondary outcome measures, which comprised of standard clinical tests, we formed composite scores of individual test measures (mean percentage of correct answers in all the measures included) in order to pool data and reduce the number of variables. Reasoning was assessed by using the Similarities and Block design subtests of the Wechsler Adult Intelligence Scale IV. ${ }^{81}$ Verbal memory was assessed by using the Word Lists I and II subtests of the Wechsler Memory Scale III (WMS-III) ${ }^{82}$ and the Digit Span subtest of WAISIV. ${ }^{81}$ Motor skills were assessed with the Box and Block test, the Action Research Arm Test, and the Purdue Peg Board Test. ${ }^{83-86}$

Statistical analyses. Statistical analyses of the behavioural data were performed using SPSS (version 25$).{ }^{87}$ In order to control possible bias introduced by missing data, an intention-to-treat (ITT) analysis was performed on the dataset of 39 (AB: $n=20, B A: n=19$ ) subjects who participated in the baseline measurement (one subject who did not participate in any measurements was discarded from the analysis due to insufficient data). ${ }^{88}$ Missing observations were imputed from TP1 and TP2 using multiple imputation, which is considered to be a reliable method when handling data missing under various missingness mechanisms. ${ }^{89}$ We found that there was significant relationship between background variables (belonging to BA-group/delayed treatment start, longer PTA and worse injury outcome, lower education level) and missing values. Because the absolute amount of missing data was relatively small and most important cases were identified, we conclude that missing value structure was missing at random (MAR). Twenty parallel datasets, which is generally considered to be a sufficient number to reduce sampling variability from the imputation process, were created using fully conditional specification imputation method. ${ }^{88,90}$ All demographic and clinical background variables (see Table 1) in addition to group allocation and outcome variables were included in the model as predictors; categorical variables were included using dummy-coding. Linear mixed model analyses (LMM) were conducted for the multiply imputed data. The model included main effects and interaction between group ( $A B / B A)$ and time points. Random intercept model, which is a special case of more general LMM framework, was used to account the within subject variation. These analyses were performed using the method described by van Ginkel and Kroonenberg, which involves reformulation of the ANOVA model as a regression model using effect coding of the predictors and applying existing combination rules for regression models in order to pool the F-tests. ${ }^{91}$ This procedure is equivalent to a repeated measures (mixed-model) ANOVA. Significant findings were further assessed by conducting a within-subject repeated measures ANOVA (AB group with complete data) / LMM (BA with imputed data) over the three time points separately for both groups in order to assess the possible longitudinal intervention effects. Given the uncertainty involved in performing data imputation in a relatively small sample like 
ours, we performed also a per-protocol (PP) analyses to verify the results from ITT analysis in a smaller dataset of subjects who adhered to the study protocol and participated in all measurements including MRI. ${ }^{92}$ One participant in the BA group reported having practiced piano intensively (3 hours/week), with both piano lessons and independent training at home, between TP1-TP2 and was therefore excluded from the PP analysis, making the final PP sample 25 patients (AB: $n=16, B A: n=9$ ). The PP analysis was limited to the outcome measures that yielded significant findings in the ITT analysis to assess their sensitivity.

\section{MRI data acquisition and preprocessing}

High-resolution T1-3D images were obtained with a 3T Philips Achieva MRI scanner (Philips Medical Systems) using an 8-channel SENSE head coil of the HUS Helsinki Medical Imaging Center at HUCH (flip angle $=15^{\circ}$; $\mathrm{TR}=9.9 \mathrm{~ms} ; \mathrm{TE}=4.60 \mathrm{~ms}$; voxel size $=0.88 \times 0.88 \times 0.88 \mathrm{~mm}$ ). Twenty-five patients completed the scanning sessions in the three time points (AB: $n=16, B A: n=9)$. Only patients with T1 images from TP1-TP2-TP3 were included in the analysis. Focal brain lesions were detected in 12 TBI patients.

Data were preprocessed using a standard voxel-based morphometry (VBM) pipeline in Statistical Parametric Mapping software (SPM12, Wellcome Department of Cognitive Neurology, University College London) running under Matlab Release 2017a (The MathWorks, Inc., Natick, MA, US). As the presence of lesions may influence the normalization algorithm, cost function masks (CFM) were defined for the 12 patients with focal brain lesions to achieve optimal normalization with no postregistration lesion shrinkage or out-of-brain distortion. ${ }^{93}$ Binary masks of the lesioned areas were obtained by manually drawing, on a slice-by-slice basis, the precise boundaries of the lesion directly into the T1 image from the TP1 session with MRIcron 2 May 2016 release (https://www.nitrc.org/projects/mricron). Accuracy of the CFM was validated by an expert neuroradiologist (author J.P.) who assessed multiple modalities of neuroimaging data acquired at TP1 (T1weighted, FLAIR). Next, within-subject T1 images from all time points were coregistered using the T1 from TP1 as reference image to ensure that they remained in spatial alignment with the T1 and CFM from this acquisition. All images and CFM were oriented to the AC before this coregistration step. Unified segmentation with medium regularization was applied to T1 images (masked with CFM for those patients with visible lesions on the T1) and grey matter (GM), white matter (WM), and cerebrospinal fluid (CSF) probability maps were obtained for each individual. ${ }^{94}$ This technique has been widely used with lesioned patients. ${ }^{95}, 96$ The preserved amount option was selected to "modulate" images and preserve the total amount of signal during the normalization to the Montreal Neurological Institute (MNI) template with a final voxel size of $1 \times 1 \times 1 \mathrm{~mm}$. The resulting images were then smoothed with a $6-\mathrm{mm}$ FWHM kernel to reduce residual interindividual variability. 


\section{Voxel-based morphometry (VBM)}

Voxelwise statistical analyses were performed in SPM12. Individual smoothed GM and WM images were entered into a second-level analysis using a Group (AB/BA) x Time (TP1/TP2/TP3) mixed-model ANOVA. Six different Group (AB>BA, BA>AB) x Time (TP2>TP1, TP3>TP2, TP3>TP1) interactions were calculated and a conjunction analysis was performed between $A B>B A \times T P 2>T P 1$ and $B A>A B \times$ TP3 $>$ TP2 contrasts. Results are reported at a whole-brain uncorrected $p<0.001$ threshold at the voxel level with a cluster extent of 50 contiguous voxels. The GMV values for the effect size were obtained from the peak coordinates of the right IFG cluster with the highest T value in each contrast. We performed a conjunction analysis in SPM (conjunction null) in order to assess the voxels that were commonly activated during the intervention period in the $A B$ and $B A$ groups.

After confirming a significant Group x Time interaction, we carried out other second-level analyses by pooling data from $A B$ and $B A$ groups: (i) before and after the intervention period using a one-sample t test $(A B$ : TP2>TP1 \& BA: TP3>TP2) and (ii) before and after the intervention vs. control period using a paired test (AB: TP2>TP1 \& BA: TP3>TP2 vs. AB: TP3>TP2 \& BA: TP2>TP1). Additional individual smoothed GM and WM images were calculated as the difference between the two time points in the intervention and control periods (AB group: intervention: TP2-TP1 and control: TP3-TP2; vice versa for the BA group) to perform these analyses. Results are reported at a whole-brain uncorrected $p<0.001$ threshold at the voxel level with a cluster extent of 50 contiguous voxels and an FWE-corrected $p<0.05$ threshold at the cluster level. The GMV values for the effect size were obtained from the peak coordinates of the right IFG cluster with the highest T value in the intervention versus control contrast.

In all second-level analyses, the intracranial volume (ICV) of each patient was entered as a nuisance covariate to account for interindividual variability. The ICV was estimated by computing the volumes of grey matter, white matter and CSF from the tissue segmentations using the SPM function spm_get_volumes and then adding up the volumes of these tissues to obtain the total ICV (in litres). Anatomical and cytoarchitectonical areas were identified using the Automated Anatomical Labeling Atlas ${ }^{97}$ and the Talairach Daemon database atlas $^{98}$ included in the xjView toolbox (http://www.alivelearn.net/xjview/).

To examine brain-behaviour correlations, we performed a region-of-interest (ROI) analysis with all significant clusters in the IFG from the pairwise comparison and computed the mean value of the individual smoothed GM and WM difference images for the control and intervention periods for each group. Bivariate correlations using two-tailed Pearson's $r$ tests were calculated between these values and individual scores from the behavioural measure that showed a significant effect in the pairwise comparisons (switching cost error rate in the NLT) separately for the intervention and control periodsRESULTS 


\section{Recruitment procedure and characteristics of the participants}

Recruitment started in March 2014 and ended in May 2017 after reaching the preset goal of 40 subjects. The last follow-up measurements were completed in November 2017. Background information regarding sociodemographic and clinical factors and musical experience is presented in Table 1. The only significant difference between the groups was detected in the deviation on causes leading to injury $(p=0.022)$. However, this difference was not considered to be of clinical importance, particularly since the traffic-related injuries involving higher energy and possibly a different recovery trajectory were evenly divided between the two groups. ${ }^{99}$ The amount of other rehabilitation (standard care) did not differ between the groups (Table 2). Also the amount of received music therapy sessions was comparable between the groups: the subjects who participated in the intervention received a mean of $17.1(S D=5.9)$ sessions of individual music therapy in the $A B$ group and $17.6(S D=5.2)$ sessions in the BA group.

\section{Effects of music therapy on behavioural outcome}

Intention-to-treat analyses

Following the ITT protocol, we first performed multiple imputation (see Methods) to replace missing values for dropped-out patients and then carried out linear mixed-model analysis $(L M M)$ in the whole sample $(n=39)$ with Time (TP1/TP2) as a within-subject factor and Group (AB/BA) as a between-subject factor for all the behavioural outcome measures to assess the short-term (pre-post) effects of music therapy compared to standard care. The F- and p-values presented were derived from the imputed data as described in methods section. Effect sizes were calculated based on the observed data using repeated measures ANOVA, since the LMM procedure does not produce $n p^{2}$ values. For the primary outcome (EF composite score), these analysis yielded a significant Time $x$ Group interaction $\left(F_{1,29}=4.374, p=0.045, n p^{2}=0.093\right)$, indicating a larger improvement in $E F$ in the $A B$ group than in the $B A$ group (Figure $2 A)$. For the secondary outcomes, set shifting (switching cost errors in the NLT) showed a significant Time $x$ Group interaction $\left(F_{1,67}=4.798, p=0.032, n p^{2}=\right.$ 0.112), with a larger reduction in switching cost error rate in the $A B$ group than in the BA group (Figure $2 B$ ). There were no other significant Time $x$ Group interactions.

In order to assess if the positive effects of music therapy on EF and set shifting were (i) maintained in the $A B$ group longitudinally and (ii) seen also in the BA group after their intervention period, we performed repeatedmeasures ANOVA for AB group and LMM for BA group with Time (TP1/TP2/TP3) as a within-subject factor. In the $A B$ group, there was significant Time main effect for $E F\left(F_{1,25}=9.258, p=0.003, n p^{2}=0.328\right)$ but not for set shifting $\left(F_{2,38}=1.854, p=0.171, \eta p^{2}=0.089\right)$. Bonferroni-corrected pairwise contrasts indicated that $E F$ 
performance improved in the AB group from TP1 to TP2 $(p=0.043)$ and from TP1 to TP3 $(p=0.003)$, but not from TP2 to TP3 $(p=0.990)$, indicating that the EF enhancement was maintained longitudinally. Within the BA group, there was no significant main effect of time in $F A B\left(F_{2,28}=0.498, p=0.952, n p^{2}=0.016\right)$ or switching $\operatorname{cost}\left(\mathrm{F}_{2,42}=0.805, p=0.453, n p^{2}=0.043\right)$

\section{Per-protocol analyses}

We performed also PP analyses to verify that the ITT results on EF and set shifting (see above) were evident also in the sample of 25 patients who had full behavioural and SMRI data from all three time points and adhered to the study protocol (see Suppl. Tables 1-2 for demographic and standard care information). In the PP analyses (Suppl. Table 3), we performed mixed-model ANOVAs to test the short-term effects of the intervention vs. control periods during the first (Time: TP1/TP2 $x$ Group: AB/BA) and the second (Time: TP2/TP3 x Group: AB/BA) study phase. In EF, there was a significant Time $x$ Group interaction from TP1 to TP2 $\left(F_{1,23}=5.86, p=0.024, n p^{2}=\right.$ 0.203 ) but not from TP2 to TP3 $\left(F_{1,23}=0.18, p=0.673, n p^{2}=0.008\right)$. In a within-subject (TP1/TP2/TP3) repeatedmeasures ANOVA, there was a significant Time effect in the $A B$ group $\left(F_{1.3,20.0}=12.66, p=0.001, \eta p^{2}=0.458\right)$ but not in the BA group $\left(F_{2,16}=0.04, p=0.960, n p^{2}=0.005\right)$. Bonferroni-corrected post hoc tests showed that EF performance improved in the AB group from TP1 to TP2 $(p=0.010)$ and from TP1 to TP3 $(p=0.003)$, but did not change from TP2 to TP3 $(p=1.000)$.

In set shifting, the Time $x$ Group interaction was marginally significant both from TP1 to TP2 $\left(F_{1,23}=3.13, p=\right.$ $\left.0.090, \eta p^{2}=0.120\right)$ and from TP2 to TP3 $\left(F_{1,23}=4.24, p=0.051, \eta p^{2}=0.156\right)$, indicating that in both groups performance improved (reduced switching cost errors) during the intervention period and declined (increased errors) during the control period. Pooling the data across groups, this was further analyzed with a paired t-test comparing the change scores of the intervention period (AB: TP2-TP1 \& BA: TP3-TP2) and control period (AB: TP3-TP2 \& BA: TP2-TP1), which showed that set shifting was significantly enhanced after the intervention compared to the control period $\left(\mathrm{t}_{24}=2.49, p=0.020\right)$.

\section{Effects of music therapy on structural neuroplasticity}

In the VBM data, we first examined the Time $x$ Group interactions with a mixed-model ANOVA. Whole-brain analyses were performed for the $A B>B A \times T P 2>T P 1$ interaction and for the $B A>A B \times T P 3>T P 2$ interaction (see Table 4) to assess changes in GMV in the group undergoing the music therapy compared to the group receiving only standard care. At a threshold of $p<0.001$ voxel-level uncorrected and $\geq 50$ voxels cluster size, both interactions yielded common clusters in the right inferior frontal gyrus (IFG, triangular part), right middle frontal 
gyrus (MFG), left cerebellum, and left fusiform gyrus, with additional clusters observed variably in either interaction in other frontal, temporal, parietal, and cingulate regions (Figure 3A \& 3B). A conjunction analysis (Table 4, Figure 3C) across both interactions revealed a region of overlap specifically in the right IFG encompassing 152 voxels, indicating that this area showed the strongest GMV changes in both groups during the intervention vs. control period. Notably, in a within-subject (TP1/TP2/TP3) repeated-measures ANOVA, there were no significant TP3 $>$ TP2 effects in the AB group or TP2>TP1 effects in the BA group, indicating that GMV did not change during the control period.

Unfortunately, none of contrasts reported above survived a FWE correction, most likely due to the small size of the sample and the individual variability in TBI neuropathology. In order to increase the statistical power of the analyses, we then pooled the data from the $A B$ and BA groups together $(n=25)$ and compared GMV changes (i) before and after the intervention period using a one-sample t test (AB: TP2>TP1 \& BA: TP3>TP2) and (ii) before and after the intervention vs. control period using a paired t test (AB: TP2>TP1 \& BA: TP3>TP2 vs. AB: TP3>TP2 \& BA: TP2>TP1). In both of these analysis (Table 5), the largest and most significant $(p<0.05$ at FWE-corrected at cluster-level) GMV change occurred again in the right IFG (see Figure 4A). Other, less significant ( $p<0.001$ uncorrected and $\geq 50$ voxels cluster size) clusters also showing GMV increases during the intervention vs. control period were in the left insula, right MFG, left IFG orbital part, medial orbitofrontal gyrus, left middle temporal gyrus, left cingulate cortex, and left cerebellum.

Finally, using the pooled sample, we performed a bivariate correlation (Pearson, two-tailed) analysis between the pre-post intervention and control period changes in GMV in the right IFG and in set shifting performance (NLT switching cost error rate). This correlation was significant only in the intervention period $\left(r=-0.41, r^{2}=\right.$ $0.17, p=0.043$; Figure $4 \mathrm{~B}$ ), indicating that the enhancement in set shifting ability induced by the music therapy was associated with structural neuroplasticity in the right IFG.

\section{Evaluation of harms}

The intervention was safe for the subjects. Participants or their caregivers did not report any significant harms, and the drop-out rate after starting the intervention was remarkably low (3\%). Some of the subjects reported short-term fatigue due to the extra effort needed to participate in the intervention and evaluations. This is understandable considering the low energy levels often linked to TBI.

\section{DISCUSSION}

This study is to our knowledge the first randomized controlled study mapping the cognitive, motor, and neurostructural effects of neurological music therapy after TBI. Our results from both cognitive and volumetric 
measures point to an intervention effect on prefrontally mediated cognitive functions. Compared to the BA group, general EF performance [Frontal Assessment Battery (FAB) score] of the AB group improved over the intervention period, and the positive effect endured over the follow-up period. In both groups, there was also improvement in set shifting [Number-Letter Task (NLT)] during the intervention period compared to the control period. In the VBM analysis, this intervention effect was coupled with the increase of GMV specifically in the right IFG, which also correlated with the observed improvement in set shifting. Together, these findings suggest that neurological music therapy can enhance EF and induce fine-grained neuroanatomical changes after TBI.

The enhancement of general $E F(F A B)$ observed in the $A B$ group over the intervention period and in the 6month post-intervention follow-up is in line with accumulating research evidence pointing towards transfer effects from musical skills to EF. ${ }^{13-22}$ These effects have been reported both in the developing brain of children and adult musicians, as well as in training studies with musically naïve adults, both younger and older, indicating that EF is malleable with musical training throughout the lifespan. A possible mechanism behind these transfer effects is that musical activities require high-level cognitive skills, particularly EF, attention, and working memory, which enable us to focus on, maintain, and manipulate musical information ${ }^{100,}{ }^{101}$ and which are subserved especially by a network of frontal brain regions. ${ }^{100,101}$ The neural networks recruited during musical activities are therefore likely shared with other cognitive processes. In our study, the observed effects of musical training on general EF endured over the 3-month post-intervention follow-up period, pointing to long-lasting positive cognitive effects of the therapy. However, as some patients in the AB group, being motivated and inspired by the intervention, reported having continued musical activities on a regular basis on their own after the intervention period, this longitudinal result may partly reflect the continued practice.

The set shifting abilities improved during the intervention period, but the effect was no longer detected after the follow-up period. When comparing change in both groups $(A B+B A)$ during intervention and control period, $a$ pattern of deterioration of performance was detected during control period. Our results suggest that in this more difficult and cognitively demanding EF task (switching), there appears to be a trend towards weakening and music therapy can temporarily reverse this course to a positive direction. These findings are well in line with previous studies showing that the time course of the TBI recovery process is complex, and both cognitive enhancement and deterioration can take place. ${ }^{45-47}$ However, determining the long-term rehabilitation effect on set switching would require a larger study with a different design and a longer intervention and follow-up periods.

The observed link between enhanced set shifting and the music intervention is intuitively appealing and supported by evidence from studies of musical expertise: playing music requires reacting flexibly to surrounding stimuli depending on the context, particularly when playing together with others. Studies in healthy subjects have shown that musical training is associated with better set shifting ability, ${ }^{19-21,102}$ although some 
studies have not found this effect. ${ }^{103,104}$ Interestingly, since the shifting task was visual in nature (although linguistic strategies were likely used as well), the results point to modality-general effects of music, which is supported by previous studies. ${ }^{103,105}$ However, it should also be borne in mind that even if music in itself is an auditory stimulus, playing an instrument requires additionally integration of visuospatial and somatosensory information, which could lead to modality-specific training effects in these areas as well. Finally, the music intervention was not associated with any gains in upper-extremity motor functions. This may be due to (i) the intervention being primarily geared towards cognitive rehabilitation and (ii) cognitive deficits, but not motor deficits, being an inclusion criteria in the study, which led to motor deficits were underrepresented in our sample.

The improvement of general EF and set shifting, induced by the music intervention is an important clinical finding considering the commonness of executive dysfunction in the TBI population and its highly debilitating effect on functional outcome. ${ }^{106,107}$ Problems in EF and set shifting are seen in everyday life as dysfunctional action patterns characterized by poor flexibility and perseveration tendencies. Clinically, our results are in line with previous TBI intervention studies utilizing music. ${ }^{63-65}$ Thaut et al. (2009) reported an immediate positive effect of a single session on neurological music therapy on mental flexibility (indicated by the Trail Making Test), which nicely fits together with our result on the enhanced task set shifting performance. Compared to the recent study by Vik et al. (2018), ${ }^{65}$ our results converge on showing an effect of the music intervention on cognitive performance, albeit on different measures: Vik et al. found an effect on verbal learning (indicated by the California Verbal Learning Test) whereas we did not observe any effects on verbal memory or working memory updating. This is likely due to differences in patient characteristics. In the Vik et al. study, the patients had mild TBI and the intervention focused more on learning to play new songs which likely targets memory functions more than our intervention.

In the VBM analyses, we found that GMV in the right inferior frontal gyrus (IFG, in particular its foremost part, the triangular part) increased significantly in both the $A B$ and $B A$ groups during the music intervention period, both when the groups were compared to each other across time (contrasts $A B>B A x$ TP2 $>T P 1$ and $B A>A B x$ TP3>TP2) and when pooled and compared to the control period. This finding is supported by evidence from fMRI studies in healthy subjects showing that right IFG has an important role in monitoring and sequencing of auditory information and musical syntactic processing, ${ }^{108-111}$ as well as structural MRI studies showing that the cortical thickness and volume of this region is enhanced by musical training ${ }^{112}$ and undermined by musical deficits (amusia). ${ }^{113-116}$ Importantly, we also found that greater GMV in the right IFG correlated with better performance in the NLT, which is consistent with the role of the right IFG in mental set shifting and with recent evidence showing that musical training reduces switching costs and can contribute to increased efficiency in mental set shifting. ${ }^{19,117}$ In the same vein, a very recent study has reported that greater IFG activity correlated 
with improvements in set shifting performance after meditative exercise training (Tai Chi Chuan) in elderly persons, also suggesting that the linkage between IFG and set shifting is malleable to intervention. ${ }^{118}$

Other regions which most consistently showed an increase in GMV after the music therapy when comparing the $A B$ and $B A$ groups across time and when contrasting the intervention and control period across patients were the right middle frontal gyrus (MFG) as well as the left superior frontal gyrus (SFG), cingulate cortex, insula, and cerebellum. The MFG/SFG has been implicated in many domain-general cognitive functions, including attention and working memory. ${ }^{119,} 120$ It also has a functional role in music cognition, including melody discrimination, production and improvisation as well as the evaluation and representation of the emotional content of music and episodic memory retrieval. ${ }^{121,122}$ Increases in GMV in the SFG have also been reported after a music listening intervention in stroke patients. ${ }^{26}$ Cingulate, insular, and cerebellar regions are known to play a role in multiple aspects of music processing, including melody and rhythm perception, ${ }^{123-126}$ emotional processing of music, ${ }^{110,}, 127$ music improvisation, ${ }^{128-130}$ and sensorimotor integration and learning of music, ${ }^{131}$ and they also show structural and functional changes as result of musical training. ${ }^{132-134}$ The cingulate and insula are also closely linked to the salience network of the brain which has been suggested to underlie higherlevel executive, attentional, and affective processes and show enhanced integrity in musically trained persons. ${ }^{132}$ In our study, the regions listed above are most likely associated with the cognitive and motivational learning aspects of the music intervention, especially related to the perception and production of the rhythmic and melodic sequences trained during the intervention, although no direct correlations with the behavioural outcome were observed.

In addition to these prefrontal, limbic and cerebellar areas, increases in GMV in the intervention vs control period were also found in the left middle (MTG) and inferior temporal gyrus (ITG). The temporal lobe hosts the primary auditory cortex as well as secondary associative areas in the superior, middle and inferior temporal gyri, which are key components of the ventral stream specialized in auditory object recognition. ${ }^{29,} 135$ The MTG is consistently activated during music perception and imagery. ${ }^{136-140}$ In line with this functional role, GMV decreases in the MTG have been reported in persistent amusia in stroke patients. ${ }^{141}$ The increased GMV in the ITG is in agreement with previous studies of musical expertise showing that professional and amateur musicians have greater GMV in this region than non-musicians. ${ }^{142}$ Since the ITG is involved in multimodal processing ${ }^{143}$ including action choice prompted by visual stimuli144, it is conceivable that the assisted music playing with Figure notes, in which the TBI patient learnt to associate a symbol with a particular note, contributed to shape this structural plasticity. ${ }^{145}$

While the cognitive and structural neuroimaging results of the study are promising, providing the first-ever evidence from an RCT that neurological music therapy can be effective in enhancing the recovery of EF coupled also with GMV changes, the study does has some notable limitations. The first limitation is the 
relatively small sample size (39 patients in the behavioural analyses and 25 in the VBM analyses), which naturally reduces the statistical power. This is a challenging patient population, and finding suitable participants that met the original inclusion criteria was highly demanding. For this reason, we were in fact forced to loosen the inclusion criteria regarding the time from injury, now covering two years after injury compared to the initially planned 6 months. This means that some of our patients may already have passed the most optimal neurobiological time window for cognitive and motor recovery. ${ }^{146,147}$ However, more recent studies have provided evidence for neuroplastic changes induced by music supported therapy associated with motor recovery in chronic stroke patients. ${ }^{39,148,149}$ These findings indirectly suggest that experiencedependent plasticity driven by musical training could also take place in patients with brain injury at the chronic stage. In the current study, the small sample size of the current dataset prevents a fine-grained analysis of what are the differences and commonalities in the patterns of volumetric changes and cognitive recovery at the acute, subacute and chronic stages. Thus we are not able to disentangle the effect of spontaneous remission processes occurring at the acute and subacute stages compared to the chronic stage. Future longitudinal studies with a stratification of patients by time since injury would be warranted to explicitly test whether the cognitive and neuroplastic changes induced by the music therapy differ between the acute/subacute and chronic stages. $39,148,149$

Second, the design of the study (cross-over RCT with two groups) precludes comparing the efficacy of the music therapy to another control intervention and determining its long-term impact. The cross-over design was chosen for practical reasons, to minimize drop-outs that would be expected in a standard care-only control group, especially in the TBI population. However, because of the possible intervention carry-over effects in the $A B$ group after the treatment, we were compelled to focus our main analyses between the first two measurements. In addition to this, the high drop-out rate in BA group lead to the fact that no reliable conclusions could be drawn from the effectiveness of music therapy in this group. We did not detect any changes in the general EF within BA group in the imputed data set. However, only $13 / 20$ (65\%) of the patients completed the study to their post-intervention time point (TP3). The drop-outs were due to lack of motivation and energy to continue participation, which are common in the TBI population, 4,150 and were likely linked to the long waiting period before receiving the intervention in the present study. In future, a larger three-arm parallel-group RCT with music therapy, another (control) therapy, and no intervention arms, as well as a longitudinal post-intervention follow-up for all groups would be warranted. Third, the music intervention was a multicomponent intervention with three different modules (rhythmical training, structured cognitive-motor training, assisted music playing) and one overarching component across modules (musical improvisation), which makes it impossible to discern how each of these contributed to the observed effects of the intervention. The advantage was that the intervention was flexible and individually adjustable to answer the differing rehabilitation needs of the TBI patients who represent a heterogeneous group. This makes our findings 
generalizable to a wide range of TBI patients with varying degrees of cognitive impairment. Time since injury was limited in our sample to a maximum of two years after injury, which is why the efficacy of the treatment in TBI patients injured outside this time window is yet to be explored. Despite these limitations, our study suggests that neurological music therapy is a very promising, unique, and highly applicable tool in TBI neurorehabilitation, with power to enhance high-level cognitive functions and induce fine-grained neuroplasticity changes in the recovering brain.

\section{Acknowledgements}

We would like to thank the multidisciplinary team of experts participating in the planning and data collection: Music therapist Esa Ala-Ruona participated in planning of the intervention. Professor Mari Tervaniemi and neurologist Anne Vehmas took part in the initial planning of the study. Research nurse Veera Lotvonen recruited the participants with the help of neuropsychologists Jaana Sarajuuri and Titta Ilvonen. Occupational therapists Mariella Ojaniemi, Elina Lassila and Jutta Stenbäck and physiotherapists Maiju Lehtonen and Anu Mänttäri collected the motor data. Above all we want to thank the TBI patients and their family members who participated in the study.

\section{Funding}

Financial support was provided by the Academy of Finland (grants no. 277693, 299044, 306625), University of Helsinki (grant no. 313/51/2013), Social Insurance Institution of Finland (grant no. 18/26/2013) Yrjö Johansson Foundation (grant no. 6464) and Finnish Association of People with Physical Disabilities \& Helsinki Uusimaa Hospital district (grants no. 461/13/01/00/2015 ja 154/13/01/2016).

\section{Author Disclosure Statement}

No competing financial interests exist. 


\section{REFERENCES}

1. Maas, A.I.R., Menon, D.K., Adelson, P.D., Andelic, N., Bell, M.J., Belli, A., Bragge, P., Brazinova, A., Büki, A., Chesnut, R.M., Citerio, G., Coburn, M., Cooper, D.J., Crowder, A.T., Czeiter, E., Czosnyka, M., Diaz-Arrastia, R., Dreier, J.P., Duhaime, A.C., Ercole, A., van Essen T.A., Feigin, V.L., Gao, G., Giacino, J., Gonzalez-Lara, L.E., Gruen, R.L., Gupta, D., Hartings, J.A., Hill, S., Jiang, J.Y., Ketharanathan, N., Kompanje, E.J.O., Lanyon, L., Laureys, S., Lecky, F., Levin, H., Lingsma, H.F., Maegele, M., Majdan, M., Manley, G., Marsteller, J., Mascia, L., McFadyen, C., Mondello, S., Newcombe, V., Palotie, A., Parizel, P.M., Peul, W., Piercy, J., Polinder, S., Puybasset, L., Rasmussen, T.E., Rossaint, R., Smielewski, P., Söderberg, J., Stanworth, S.J., Stein, M.B., von Steinbüchel, N., Stewart, W., Steyerberg, E.W., Stocchetti, N., Synnot, A., Te Ao, B., Tenovuo, O., Theadom, A., Tibboel, D., Videtta, W., Wang, K.K.W., Williams, W.H., Wilson, L., Yaffe, K. and InTBIR Participants and Investigators. (2017). Traumatic brain injury: integrated approaches to improve prevention, clinical care, and research. Lancet Neurol 16, 987-1048.

2. Hoofien, D., Gilboa, A., Vakil, E. and Donovick, P.J. (2001). Traumatic brain injury (TBI) 10-20 years later: a comprehensive outcome study of psychiatric symptomatology, cognitive abilities and psychosocial functioning. Brain Inj 15, 189-209.

3. Dikmen, S.S., Corrigan, J.D., Levin, H.S., Machamer, J., Stiers, W. and Weisskopf, M.G. (2009). Cognitive outcome following traumatic brain injury. J Head Trauma Rehabil 24, 430-438.

4. Cantor, J.B., Gordon, W. and Gumber, S. (2013). What is post TBI fatigue? NeuroRehabilitation 32, 875-883.

5. Langlois, J.A., Rutland-Brown, W. and Wald, M.M. (2006). The epidemiology and impact of traumatic brain injury: A brief overview. J Head Trauma Rehabil 21, 375-378.

6. Stuss, D.T. (2011). Traumatic brain injury: Relation to executive dysfunction and the frontal lobes. Curr Opin Neurol 24, 584-589.

7. Sharp, D.J., Scott, G. and Leech, R. (2014). Network dysfunction after traumatic brain injury. Nat Rev Neurol 10, 156166.

8. Ham, T.E. and Sharp, D.J. (2012). How can investigation of network function inform rehabilitation after traumatic brain injury? Curr Opin Neurol 25, 662-669.

9. Burgess, P.W. and Stuss, D.T. (2017). Fifty years of prefrontal cortex research: Impact on assessment. J Int Neuropsychol Soc 23, 755-767.

10. Friedman, N.P. and Miyake, A. (2017). Unity and diversity of executive functions: Individual differences as a window on cognitive structure. Cortex 86, 186-204.

11. Krpan, K.M., Levine, B., Stuss, D.T. and Dawson, D.R. (2007). Executive function and coping at one-year post traumatic brain injury. J Clin Exp Neuropsychol 29, 36-46.

12. Cicerone, K., Levin, H., Malec, J., Stuss, D. and Whyte, J. (2006). Cognitive rehabilitation interventions for executive function: Moving from bench to bedside in patients with traumatic brain injury. J Cogn Neurosci 18, 1212-1222.

13. Carpentier, S.M., Moreno, S. and McIntosh, A.R. (2016). Short-term music training enhances complex, distributed neural communication during music and linguistic tasks. J Cogn Neurosci 28, 1603-1612.

14. Jaschke, A.C., Honing, H. and Scherder, E.J.A. (2018). Longitudinal analysis of music education on executive functions in primary school children. Fron Neuroscience 12, 103.

15. Putkinen, V., Tervaniemi, M., Saarikivi, K. and Huotilainen, M. (2015). Promises of formal and informal musical activities in advancing neurocognitive development throughout childhood. Ann N Y Acad Sci 1337, 153-162.

16. Moreno, S., Bialystok, E., Barac, R., Schellenberg, E.G., Cepeda, N.J. and Chau, T. (2011). Short-term music training enhances verbal intelligence and executive function. Psychol Sci 22, 1425-1433.

17. Sachs, M., Kaplan, J., Der Sarkissian, A. and Habibi, A. (2017). Increased engagement of the cognitive control network associated with music training in children during an fMRI Stroop task. PLoS One 12, e0187254.

18. Habibi, A., Damasio, A., llari, B., Elliott Sachs, M. and Damasio, H. (2018). Music training and child development: a review of recent findings from a longitudinal study. Ann N Y Acad Sci 1423, 73-81.

19. Moradzadeh, L., Blumenthal, G. and Wiseheart, M. (2015). Musical training, bilingualism, and executive function: a closer look at task switching and dual-task performance. Cogn Sci 39, 992-1020.

20. Zuk, J., Benjamin, C., Kenyon, A. and Gaab, N. (2014). Behavioral and neural correlates of executive functioning in musicians and non-musicians. PLoS One 9, e99868.

21. Bugos, J.A., Perlstein, W.M., McCrae, C.S., Brophy, T.S. and Bedenbaugh, P.H. (2007). Individualized piano instruction enhances executive functioning and working memory in older adults. Aging Ment Health 11, 464-471. 22. Strong, J.V. and Mast, B.T. (2019). The cognitive functioning of older adult instrumental musicians and nonmusicians. Neuropsychol Dev Cogn B Aging Neuropsychol Cogn 26, 367-386.

23. Belfi, A.M., Evans, E., Heskje, J., Bruss, J. and Tranel, D. (2017). Musical anhedonia after focal brain damage. Neuropsychologia 97, 29-37. 
24. Raglio, A., Attardo, L., Gontero, G., Rollino, S., Groppo, E. and Granieri, E. (2015). Effects of music and music therapy on mood in neurological patients. World J Psychiatry 5, 68-78.

25. Särkämö, T., Tervaniemi, M., Laitinen, S., Forsblom, A., Soinila, S. and Mikkonen, M. (2008). Music listening enhances cognitive recovery and mood after middle cerebral artery stroke. Brain 131, 866-876.

26. Särkämö, T., Ripollés, P., Vepsäläinen, H., Autti, T., Silvennoinen, H.M., Salli, E., Laitinen, S., Forsblom, A., Soinila, S. and Rodríguez-Fornells, A. (2014). Structural Changes Induced by Daily Music Listening in the Recovering Brain after Middle Cerebral Artery Stroke: A Voxel-Based Morphometry Study. Front Hum Neurosci 8, 245.

27. Soto, D., Funes, M.J., Guzmán-García, A., Warbrick, T., Rotshtein, P. and Humphreys, G.W. (2009). Pleasant music overcomes the loss of awareness in patients with visual neglect. Proc Nat. Acad Sci USA 106, 6011-6016.

28. Blood, A.J. and Zatorre, R.J. (2001). Intensely pleasurable responses to music correlate with activity in brain regions implicated in reward and emotion. Proc Natl Acad Sci USA 98, 11818-11823.

29. Zatorre, R.J. and Salimpoor, V.N. (2013). From perception to pleasure: Music and its neural substrates. Proc Natl Acad Sci USA 110, 10430-10437.

30. Koelsch, S. (2014). Brain correlates of music-evoked emotions. Nat Rev Neurosci 15, 170.

31. Marin, R.S. and Wilkosz, P.A. (2005). Disorders of Diminished Motivation. Journal Head Trauma Rehabil 20, $377-$ 388.

32. Grau-Sanchez, J., Duarte, E., Ramos-Escobar, N., Sierpowska, J., Rueda, N., Redon, S., Veciana de Las Heras, M., Pedro, J., Särkämö, T. and Rodríguez-Fornells, A. (2018). Music-supported therapy in the rehabilitation of subacute stroke patients: a randomized controlled trial. Ann N Y Acad Sci.

33. Greene, C.M., Bahri, P. and Soto, D. (2010). Interplay between affect and arousal in recognition memory. PLoS One 5, e11739.

34. Särkämö, T. and Soto, D. (2012). Music listening after stroke: beneficial effects and potential neural mechanisms. Ann N Y Acad Sci 1252, 266-281.

35. Bradt, J., Magee, W.L., Dileo, C., Wheeler, B.L. and McGilloway, E. (2010). Music therapy for acquired brain injury. Cochrane Database Syst Rev, Cd006787.

36. Schneider, S., Münte, T., Rodriguez-Fornells, A., Sailer, M. and Altenmüller, E. (2010). Music-Supported Training is More Efficient than Functional Motor Training for Recovery of Fine Motor Skills in Stroke Patients. Music Percept 27, 271-280.

37. Rojo, N., Amengual, J., Juncadella, M., Rubio, F., Camara, E., Marco-Pallares, J., Schneider, S., Veciana, M., Montero, J., Mohammadi, B., Altenmüller, E., Grau, C., Münte, T.F. and

Rodriguez-Fornells A. (2011). Music-Supported Therapy induces plasticity in the sensorimotor cortex in chronic stroke: A single-case study using multimodal imaging (fMRI-TMS). Brain Inj 25, 787-793.

38. Rodriguez-Fornells, A., Rojo, N., Amengual, J.L., Ripollés, P., Altenmüller, E. and Münte, T.F. (2012). The involvement of audio-motor coupling in the music-supported therapy applied to stroke patients. Ann N Y Acad Sci 1252, 282-293.

39. Ripollés, P., Rojo, N., Grau-Sánchez, J., Amengual, J.L., Càmara, E., Marco-Pallarés, J., Juncadella, M., Vaquero, L., Rubio, F., Duarte, E., Garrido, C., Altenmüller, E., Münte T.F. and Rodríguez-Fornells, A. (2016). Music supported therapy promotes motor plasticity in individuals with chronic stroke. Brain Imaging Behav 10, 1289-1307.

40. Ding, K., Marquez de la Plata, C., Wang, J.Y., Mumphrey, M., Moore, C., Harper, C., Madden, C.J., McColl, R., Whittemore, A., Devous, M.D. and Diaz-Arrastia, R. (2008). Cerebral atrophy after traumatic white matter injury: Correlation with acute neuroimaging and outcome. J Neurotrauma 25, 1433-1440.

41. Bendlin, B.B., Ries, M.L., Lazar, M., Alexander, A.L., Dempsey, R.J., Rowley, H.A., Sherman J.E. and Johnson, S.C.. (2008). Longitudinal changes in patients with traumatic brain injury assessed with diffusion-tensor and volumetric imaging. Neuroimage 42, 503-514.

42. Sidaros, A., Skimminge, A., Liptrot, M.G., Sidaros, K., Engberg, A.W., Herning, M., Paulson, O.B., Jernigan, T.L. and Rostrup, E. (2009). Long-term global and regional brain volume changes following severe traumatic brain injury: A longitudinal study with clinical correlates. Neurolmage 44, 1-8.

43. Farbota, K.D.M., Sodhi, A., Bendlin, B.B., McLaren, D.G., Xu, G., Rowley, H.A. and Johnson, S.C. (2012). Longitudinal volumetric changes following traumatic brain injury: A tensor-based morphometry study. J Int Neuropsychol Soc 18, 1006-1018.

44. Cole, J.H., Jolly, A., de Simoni, S., Bourke, N., Patel, M.C., Scott, G. and Sharp, D.J. (2018).Spatial patterns of progressive brain volume loss after moderate-severe traumatic brain injury. Brain 141, 822-836.

45. Himanen, L., Portin, R., Isoniemi, H., Helenius, H., Kurki, T. and Tenovuo, O. (2006). Longitudinal cognitive changes in traumatic brain injury: a 30-year follow-up study. Neurology 66, 187-192.

46. Rabinowitz, A.R., Hart, T., Whyte, J. and Kim, J. (2018). Neuropsychological Recovery Trajectories in Moderate to Severe Traumatic Brain Injury: Influence of Patient Characteristics and Diffuse Axonal Injury. J Int Neuropsychol Soc 24, 237-246. 
47. Vasquez, B.P., Tomaszczyk, J.C., Sharma, B., Colella, B. and Green, R.E.A. (2018). Longitudinal Recovery of Executive Control Functions After Moderate-Severe Traumatic Brain Injury: Examining Trajectories of Variability and ExGaussian Parameters. Neurorehabil Neural Repair 32, 191-199.

48. Tomaszczyk, J.C., Green, N.L., Frasca, D., Colella, B., Turner, G.R., Christensen, B.K. and Green, R.E. (2014). Negative neuroplasticity in chronic traumatic brain injury and implications for neurorehabilitation. Neuropsychol Rev 24, 409-427.

49. Miller, L.S., Colella, B., Mikulis, D., Maller, J. and Green, R.E. (2013). Environmental enrichment may protect against hippocampal atrophy in the chronic stages of traumatic brain injury. Front Hum Neurosci 7, 506.

50. de la Tremblaye, P.B., Cheng, J.P., Bondi, C.O. and Kline, A.E. (2019). Environmental enrichment, alone or in combination with various pharmacotherapies, confers marked benefits after traumatic brain injury. Neuropharmacology $145,13-24$.

51. Glassman, L.R. (1991). Music therapy and bibliotherapy in the rehabilitation of traumatic brain injury: A case study. Arts Psychother 18, 149-156.

52. Baker, F., Wigram, T. and Gold, C. (2005). The effects of a song-singing programme on the affective speaking intonation of people with traumatic brain injury. Brain Inj 19, 519-528.

53. Guétin, S., Soua, B., Voiriot, G., Picot, M.C. and Hérisson, C. (2009). The effect of music therapy on mood and anxiety-depression: An observational study in institutionalised patients with traumatic brain injury. Ann Phys Rehabil Med 52, 30-40.

54. Magee, W.L. and Davidson, J.W. (2002). The effect of music therapy on mood states in neurological patients: a pilot study. J Music Ther 39, 20-29.

55. Formisano, R., Vinicola, V., Penta, F., Matteis, M., Brunelli, S. and Weckel, J.W. (2001). Active music therapy in the rehabilitation of severe brain injured patients during coma recovery. Ann Ist Super Sanita 37, 627-630.

56. Grimm, T. and Kreutz, G. (2018). Music interventions in disorders of consciousness (DOC) - a systematic review. Brain Inj 32, 704-714.

57. Tamplin, J. (2008). A pilot study into the effect of vocal exercises and singing on dysarthric speech.

NeuroRehabilitation 23, 207-216.

58. Baker, F.A., Tamplin, J., MacDonald, R.A.R., Ponsford, J., Roddy, C., Lee, C. and Rickard, N. (2017). Exploring the

self through songwriting: An analysis of songs composed by people with acquired neurodisability in an inpatient rehabilitation program. J Music Ther 54, 35-54.

59. Baker, F.A., Rickard, N., Tamplin, J. and Roddy, C. (2015). Flow and meaningfulness as mechanisms of change in self-concept and well-being following a songwriting intervention for people in the early phase of neurorehabilitation. Front Hum Neurosci 9.

60. Roddy, C., Rickard, N., Tamplin, J., Lee, Y.-E.C. and Baker, F.A. (2018). Exploring self-concept, wellbeing and distress in therapeutic songwriting participants following acquired brain injury: A case series analysis. Neuropsychol Rehabil 21, 1-21.

61. Kim, S.J., Shin, Y.-K., Yoo, G.E., Chong, H.J. and Cho, S.-R. (2016). Changes in gait patterns induced by rhythmic auditory stimulation for adolescents with acquired brain injury. Ann N Y Acad Sci 1385, 53-62.

62. Hurt, C.P., Rice, R.R., McIntosh, G.C. and Thaut, M.H. (1998). Rhythmic auditory stimulation in gait training for patients with traumatic brain injury. J Music Ther 35, 228-241.

63. Thaut, M.H., Gardiner, J.C., Holmberg, D., Horwitz, J., Kent, L., Andrews, G., Donelan, B. and McIntosh, G.R. (2009). Neurologic music therapy improves executive function and emotional adjustment in traumatic brain injury rehabilitation. Ann N Y Acad Sci 1169, 406-416.

64. Lynch, C. and LaGasse, A.B. (2016). Training endogenous task shifting using music therapy: A feasibility study. J Music Ther 53, 279-307.

65. Vik, B.M.D., Skeie, G.O., Vikane, E. and Specht, K. (2018). Effects of music production on cortical plasticity within cognitive rehabilitation of patients with mild traumatic brain injury. Brain Inj 32, 634-643.

66. Traumatic Brain Injury. Current Care Guidelines. Working group set up by the Finnish Medical Society Duodecim, Finnish Neurological Society, Societas Medicinae Physicalis et Rehabilitationis Fenniae, Finnish Neurosurgical Society, Finnish Neuropsychological Society and Assocication of Finnish Insurance Medicine Doctors, Helsinki. Helsinki: The Finnish Medical Society Duodecim, 2008 (referred 1.9.2017). Available online at: www.kaypahoito.fi

67. Schneider, S., Schönle, P.W., Altenmüller, E. and Münte, T.F. (2007). Using musical instruments to improve motor skill recovery following a stroke. J Neurol 254, 1339-1346.

68. Wilson, J.T.L., Pettigrew, L.E.L. and Teasdale, G.M. (1998). Structured interviews for the Glasgow Outcome Scale and the Extended Glasgow Outcome Scale: Guidelines for their use. J Neurotrauma 15, 573-585.

69. Wilde, E.A., McCauley, S.R., Kelly, T.M., Weyand, A.M., Pedroza, C., Levin, H.S., Clifton, G.L., Schnelle, K.P., Shah, M.V. and Moretti, P. (2010). The neurological outcome scale for traumatic brain injury (NOS-TBI): I. Construct validity. J Neurotrauma 27, 983-989. 
70. Beck, A.T., Steer, R.A., and Brown G.K. (1996, 2005). BDI-II - Beck Depression Inventory®-II. Psychological Corporation (English). Psykologien kustannus Oy, Helsinki (Finnish).

71. Dubois, B., Slachevsky, A., Litvan, I. and Pillon, B. (2000). The FAB: A frontal assessment battery at bedside. Neurology 55, 1621-1626.

72. Rojas, N., Laguë-Beauvais, M., Belisle, A., Lamoureux, J., AlSideiri, G., Marcoux, J., et al. (2019). Frontal assessment battery (FAB) performance following traumatic brain injury hospitalized in an acute care setting. Appl Neuropsychol Adult 26, 319-330.

73. Nakaaki, S., Murata, Y., Sato, J., Shinagawa, Y., Matsui, T., Tatsumi, H. and Furukawa T.A. (2007). Reliability and validity of the Japanese version of the Frontal Assessment Battery in patients with the frontal variant of frontotemporal dementia. Psychiatry Clin Neurosci 61, 78-83.

74. Miyake, A., Friedman, N.P., Emerson, M.J., Witzki, A.H., Howerter, A. and Wager, T.D. (2000). The Unity and Diversity of Executive Functions and Their Contributions to Complex "Frontal Lobe" Tasks: A Latent Variable Analysis. Cogn Psychol 41, 49-100.

75. Martin, N., Kohen, F., Kalinyak-Fliszar, M., Soveri, A. and Laine, M. (2012). Effects of working memory load on processing of sounds and meanings of words in aphasia. Aphasiology 26, 462-493.

76. Pallesen, K.J., Brattico, E., Bailey, C.J., Korvenoja, A., Koivisto, J., Gjedde, A. and Carlson, S. (2010). Cognitive control in auditory working memory is enhanced in musicians. PLoS One 5, e11120.

77. Simon, J.R. and Rudell, A.P. (1967). Auditory S-R compatibility: the effect of an irrelevant cue on information processing. J Appl Psychol 51, 300-304.

78. Robertson, I.H., Manly, T., Andrade, J., Baddeley, B.T. and Yiend, J. (1997). 'Oops!': Performance correlates of everyday attentional failures in traumatic brain injured and normal subjects. Neuropsychologia 35, 747-758.

79. Johnson, K.A., Robertson, I.H., Kelly, S.P., Silk, T.J., Barry, E., Dáibhis, A., Watchorn, A., Keavey, M., Fitzgerald, M., Gallagher, L., Gill, M. and Bellgrovea, M.A. (2007). Dissociation in performance of children with ADHD and highfunctioning autism on a task of sustained attention. Neuropsychologia 45, 2234-2245.

80. Whyte, J., Polansky, M., Fleming, M., Coslett, H.B. and Cavallucci, C. (1995). Sustained arousal and attention after traumatic brain injury. Neuropsychologia 33, 797-813.

81. Wechsler, D. (2008). Wechsler adult intelligence scale. Fourth edition ed. Pearson Assessment (Finnish version: Psykologien kustannus, Helsinki, 2012).

82. Wechsler, D. (1997). Wechsler Memory Scale Third edition ed. San Antonio: The Psychological Corporation (Finnish version: Psykologien kustannus, Helsinki, 2008).

83. Mathiowetz, V., Volland, G., Kashman, N. and Weber, K. (1985). Adult norms for the Box and Block Test of manual dexterity. Am J Occup Ther 39, 386-391.

84. Lyle, R.C. (1981). A performance test for assessment of upper limb function in physical rehabilitation treatment and research. Int J Rehabil Res 4, 483-492.

85. (1948). Purdue Pegboard. Lafayette Instrument Company, Lafayette.

86. Buddenberg, L.A. and Davis, C. (2000). Test-retest reliability of the purdue pegboard test. Am J Occup Ther 54, 555-558.

87. IBM, C. (2016). IBM SPSS Statistics for Window. IBM Corp. in Armonk, NY.

88. Sterne, J.A.C., White, I.R., Carlin, J.B., Spratt, M., Royston, P., Kenward, M.G., Wood, A.M. and

Carpenter, J.R. (2009). Multiple imputation for missing data in epidemiological and clinical research: potential and pitfalls. BMJ 338, b2393.

89. van Ginkel, J.R., Linting, M., Rippe, R.C.A. and van der Voort, A. (2019). Rebutting Existing Misconceptions About Multiple Imputation as a Method for Handling Missing Data. J Pers Assess, 1-12 [Epub ahead of print].

90. Huque, M.H., Carlin, J.B., Simpson, J.A. and Lee, K.J. (2018). A comparison of multiple imputation methods for missing data in longitudinal studies. BMC Med Res Methodol 18, 168.

91. van Ginkel, J.R. and Kroonenberg, P.M. (2014). Analysis of Variance of Multiply Imputed Data. Multivariate Behav Res 49, 78-91.

92. White, I.R., Carpenter, J. and Horton, N.J. (2012). Including all individuals is not enough: lessons for intention-to-treat analysis. Clin Trials 9, 396-407.

93. Brett, M., Leff, A.P., Rorden, C. and Ashburner, J. (2001). Spatial normalization of brain Images with focal lesions using cost function masking. Neurolmage 14, 486-500.

94. Ashburner, J. and Friston, K.J. (2005). Unified segmentation. Neuroimage 26, 839-851.

95. Andersen, S.M., Rapcsak, S.Z. and Beeson, P.M. (2010). Cost function masking during normalization of brains with focal lesions: Still a necessity? Neurolmage 53, 78-84.

96. Crinion, J., Ashburner, J., Leff, A., Brett, M., Price, C. and Friston, K. (2007). Spatial normalization of lesioned brains: Performance evaluation and impact on fMRI analyses. Neurolmage 37, 866-875. 
97. Tzourio-Mazoyer, N., Landeau, B., Papathanassiou, D., Crivello, F., Etard, O., Delcroix, N., Mazoyer, B. and Joliot, M. (2002). Automated anatomical labeling of activations in SPM using a macroscopic anatomical parcellation of the MNI MRI single-subject brain. Neurolmage 15, 273-289.

98. Lancaster, J.L., Woldorff, M.G., Parsons, L.M., Liotti, M., Freitas, C.S., Rainey, L., Kochunov, P.V., Nickerson, D., Mikiten, S.A. and Fox, P.T. (2000). Automated Talairach atlas labels for functional brain mapping. Hum Brain Map 10, 120-131.

99. Majdan, M., Mauritz, W., Brazinova, A., Rusnak, M., Leitgeb, J., Janciak, I. and Wilbacher, I. (2011). Severity and outcome of traumatic brain injuries (TBI) with different causes of injury. Brain Inj 25, 797-805.

100. D'Souza, A.A., Moradzadeh, L. and Wiseheart, M. (2018). Musical training, bilingualism, and executive function: working memory and inhibitory control. Cogn Res Princ Implic 3, 11-11.

101. Hannon, E.E. and Trainor, L.J. (2007). Music acquisition: effects of enculturation and formal training on development. Trends Cogn Sci 11, 466-472.

102. Hanna-Pladdy, B. and Mackay, A. (2011). The relation between instrumental musical activity and cognitive aging. Neuropsychology 25, 378-386.

103. Slevc, L.R., Davey, N.S., Buschkuehl, M. and Jaeggi, S.M. (2016). Tuning the mind: Exploring the connections between musical ability and executive functions. Cognition 152, 199-211.

104. Bialystok, E. and DePape, A.-M. (2009). Musical expertise, bilingualism, and executive functioning. J Exp Psychol Hum Percept Perform 35, 565-574.

105. Rodrigues, A.C., Loureiro, M.A. and Caramelli, P. (2013). Long-term musical training may improve different forms of visual attention ability. Brain Cogn 82, 229-235.

106. Struchen, M.A., Clark, A.N., Sander, A.M., Mills, M.R., Evans, G. and Kurtz, D. (2008). Relation of executive functioning and social communication measures to functional outcomes following traumatic brain injury.

NeuroRehabilitation 23, 185-198.

107. Spitz, G., Ponsford, J.L., Rudzki, D. and Maller, J.J. (2012). Association between cognitive performance and functional outcome following traumatic brain injury: a longitudinal multilevel examination. Neuropsychology 26, 604-612. 108. Cheung, V.K.M., Meyer, L., Friederici, A.D. and Koelsch, S. (2018). The right inferior frontal gyrus processes nested non-local dependencies in music. Sci Rep 8, 3822.

109. Bianco, R., Novembre, G., Keller, P.E., Kim, S.-G., Scharf, F., Friederici, A.D., Villringer, A. and Sammler, D. (2016). Neural networks for harmonic structure in music perception and action. Neurolmage 142, 454-464.

110. Koelsch, S., Fritz, T., Schulze, K., Alsop, D. and Schlaug, G. (2005). Adults and children processing music: an fMRI study. Neuroimage 25, 1068-1076.

111. Tillmann, B., Koelsch, S., Escoffier, N., Bigand, E., Lalitte, P., Friederici, A.D. and von Cramon D.Y. (2006). Cognitive priming in sung and instrumental music: activation of inferior frontal cortex. Neuroimage 31, 1771-1782. 112. Bermudez, P., Lerch, J.P., Evans, A.C. and Zatorre, R.J. (2009). Neuroanatomical correlates of musicianship as revealed by cortical thickness and voxel-based morphometry. Cereb Cortex 19, 1583-1596.

113. Albouy, P., Mattout, J., Bouet, R., Maby, E., Sanchez, G., Aguera, P.-E., Daligault, S., Delpuech, C., Bertrand, O., Caclin, A. and Tillmann, B. (2013). Impaired pitch perception and memory in congenital amusia: the deficit starts in the auditory cortex. Brain 136, 1639-1661.

114. Hyde, K.L., Lerch, J.P., Zatorre, R.J., Griffiths, T.D., Evans, A.C. and Peretz, I. (2007). Cortical thickness in congenital amusia: When less is better than more. J Neurosci 27, 13028-13032.

115. Hyde, K.L., Zatorre, R.J., Griffiths, T.D., Lerch, J.P. and Peretz, I. (2006). Morphometry of the amusic brain: a twosite study. Brain 129, 2562-2570.

116. Hyde, K.L., Zatorre, R.J. and Peretz, I. (2011). Functional MRI evidence of an abnormal neural network for pitch processing in congenital amusia. Cereb Cortex 21, 292-299.

117. Oh, A., Vidal, J., Taylor, M.J. and Pang, E.W. (2014). Neuromagnetic correlates of intra- and extra-dimensional setshifting. Brain Cogn 86, 90-97.

118. Wu, M.-T., Tang, P.-F., Goh, J.O.S., Chou, T.-L., Chang, Y.-K., Hsu, Y.-C., Chen, Y.-J., Chen, N.-C., Tseng, W.-Y., Gau, S., Chiu, M.-J. and Lan, C. (2018). Task-switching performance improvements after tai chi chuan training are associated with greater prefrontal activation in older adults. Front Aging Neurosci 10, 280.

119. Boisgueheneuc, F.d., Levy, R., Volle, E., Seassau, M., Duffau, H., Kinkingnehun, S., Samson, Y., Zhang, S. and Dubois, B. (2006). Functions of the left superior frontal gyrus in humans: a lesion study. Brain 129, 3315-3328.

120. Huang, S., Seidman, L.J., Rossi, S. and Ahveninen, J. (2013). Distinct cortical networks activated by auditory attention and working memory load. Neurolmage 83, 1098-1108.

121. Escoffier, N., Zhong, J., Schirmer, A. and Qiu, A. (2013). Emotional expressions in voice and music: Same code, same effect? Hum Brain Mapp 34, 1796-1810.

122. Platel, H., Baron, J.-C., Desgranges, B., Bernard, F. and Eustache, F. (2003). Semantic and episodic memory of music are subserved by distinct neural networks. Neurolmage 20, 244-256. 
123. Platel, H., Price, C., Baron, J.C., Wise, R., Lambert, J., Frackowiak, R.S., Lechevalier, B. and Eustache, F. (1997). The structural components of music perception. A functional anatomical study. Brain 120, 229-243.

124. Thaut, M.H. (2003). Neural basis of rhythmic timing networks in the human brain. Ann N Y Acad Sci 999, 364-373. 125. Paquette, S., Fujii, S., Li, H.C. and Schlaug, G. (2017). The cerebellum's contribution to beat interval discrimination. Neuroimage 163, 177-182.

126. Thaut, M.H., Trimarchi, P. and Parsons, L. (2014). Human brain basis of musical rhythm perception: common and distinct neural substrates for meter, tempo, and pattern. Brain Sci 4, 428.

127. Blood, A.J., Zatorre, R.J., Bermudez, P. and Evans, A.C. (1999). Emotional responses to pleasant and unpleasant music correlate with activity in paralimbic brain regions. Nat Neurosci 2, 382.

128. Brown, S., Martinez, M.J. and Parsons, L.M. (2006). Music and language side by side in the brain: a PET study of the generation of melodies and sentences. Eur J Neurosci 23, 2791-2803.

129. Engel, A. and Keller, P. (2011). The perception of musical spontaneity in improvised and imitated jazz performances. Front Psychol 2, 83.

130. Villarreal, M.F., Cerquetti, D., Caruso, S., Schwarcz López Aranguren, V., Gerschcovich, E.R., Frega, A.L. and Leiguarda, R.C. (2013). Neural correlates of musical creativity: Differences between high and low creative subjects. PLoS One 8, e75427.

131. Herrojo Ruiz, M., Maess, B., Altenmuller, E., Curio, G. and Nikulin, V.V. (2017). Cingulate and cerebellar beta oscillations are engaged in the acquisition of auditory-motor sequences. Hum Brain Mapp 38, 5161-5179.

132. Luo, C., Tu, S., Peng, Y., Gao, S., Li, J., Dong, L., Gujing, L., Yongxiu, L., Hong, L. and Dezhong Y. (2014). Longterm effects of musical training and functional plasticity in salience system. J Neural Plasticity 2014, 13.

133. Hutchinson, S., Lee, L.H., Gaab, N. and Schlaug, G. (2003). Cerebellar volume of musicians. Cereb Cortex 13, 943-949.

134. Fujioka, T. and Ross, B. (2017). Beta-band oscillations during passive listening to metronome sounds reflect improved timing representation after short-term musical training in healthy older adults. Eur J Neurosci 46, 2339-2354.

135. Rauschecker, J.P. (2015). Auditory and visual cortex of primates: a comparison of two sensory systems. The Eur J Neurosci 41, 579-585.

136. Zatorre, R.J., Halpern, A.R., Perry, D.W., Meyer, E. and Evans, A.C. (1996). Hearing in the Mind's Ear: A PET Investigation of Musical Imagery and Perception. J Cogn Neurosci 8, 29-46.

137. Halpern, A.R. and Zatorre, R.J. (1999). When that tune runs through your head: a PET investigation of auditory imagery for familiar melodies. Cereb cortex 9, 697-704.

138. Janata, P. (2001). Brain electrical activity evoked by mental formation of auditory expectations and images. Brain Topogr 13, 169-193.

139. Halpern, A.R., Zatorre, R.J., Bouffard, M. and Johnson, J.A. (2004). Behavioral and neural correlates of perceived and imagined musical timbre. Neuropsychologia 42, 1281-1292.

140. Ding, Y., Zhang, Y., Zhou, W., Ling, Z., Huang, J., Hong, B. and Wang, X. (2019). Neural Correlates of Music Listening and Recall in the Human Brain. J Neurosci 39, 8112-8123

141. Sihvonen, A.J., Ripolles, P., Leo, V., Rodriguez-Fornells, A., Soinila, S. and Sarkamo, T. (2016). Neural Basis of Acquired Amusia and Its Recovery after Stroke. J Neurosci 36, 8872-8881.

142. Gaser, C. and Schlaug, G. (2003). Brain structures differ between musicians and non-musicians. J Neurosci 23, 9240-9245.

143. Zatorre, R.J., Perry, D.W., Beckett, C.A., Westbury, C.F. and Evans, A.C. (1998). Functional anatomy of musical processing in listeners with absolute pitch and relative pitch. Proc Natl Acad Sci USA 95, 3172-3177.

144. Passingham, R.E. and Toni, I. (2001). Contrasting the dorsal and ventral visual systems: guidance of movement versus decision making. Neurolmage 14, S125-131.

145. Zatorre, R.J., Belin, P. and Penhune, V.B. (2002). Structure and function of auditory cortex: music and speech.

Trends Cogn Sci 6, 37-46.

146. Kleim, J.A. and Jones, T.A. (2008). Principles of experience-dependent neural plasticity: Implications for rehabilitation after brain damage. J Speech Lang Hear Res 51, S225-S239.

147. Ruttan, L., Martin, K., Liu, A., Colella, B. and Green, R.E. (2008). Long-Term Cognitive Outcome in Moderate to Severe Traumatic Brain Injury: A Meta-Analysis Examining Timed and Untimed Tests at 1 and 4.5 or More Years After Injury. Arch Phys Med Rehabil 89, S69-S76.

148. Amengual, J.L., Rojo, N., Veciana de Las Heras, M., Marco-Pallares, J., Grau-Sanchez, J., Schneider, S., Vaquero, L., Juncadella, M., Montero, J., Mohammadi, B., Rubio, F., Rueda, N., Duarte, E., Grau, C., Altenmüller, E., Münte, T.F. and Rodríguez-Fornells, A. (2013). Sensorimotor plasticity after music-supported therapy in chronic stroke patients revealed by transcranial magnetic stimulation. PloS one 8, e61883.

149. Amengual, J.L., Munte, T.F., Marco-Pallares, J., Rojo, N., Grau-Sanchez, J., Rubio, F., Duarte, E. Grau, C. 
and Rodríguez-Fornells, A. (2014). Overactivation of the supplementary motor area in chronic stroke patients. J Neurophysiol 112, 2251-2263.

150. Marin, R.S. and Wilkosz, P.A. (2005). Disorders of Diminished Motivation. J Head Trauma Rehabil 20, 377-388. 


\section{LEGENDS}

Figure 1. Flow chart outlining the design and progress of the trial.

Figure 2. Behavioral test results from the Intention-to-treat (ITT) analysis. Frontal Assessment Battery (FAB) score and Number-Letter Task (NLT) switching cost error. The bar plots (mean \pm SEM) show changes in test scores over the three time points (TP) presented group-wise (AB/BA) from the imputed dataset (depicting the mean of 20 imputations). Significant Time x Group interactions are shown with solid grey lines and significant within-group Time main effects are shown with dashed grey lines.

Figure 3. VBM results from the mixed-model ANOVA including $25 \mathrm{TBI}$ patients and three time points (TP). (A) Group ( $A B>B A)$ x Time (TP2>TP1) interaction in grey matter volume (GMV). (B) Group (BA>AB) x Time (TP3>TP2) interaction in GMV. (C) Conjunction analysis between (A) and (B) in GMV. (D, E, F) Bar plots (mean \pm SEM) for GMV from the local maxima in the right IFG Tri cluster in (A), (B) and (C) contrasts, respectively. The results are reported in $\mathrm{MNI}$ coordinates and at an uncorrected $p<0.005$ threshold at the voxel level for visualization purposes. IFG Tri: inferior frontal gyrus triangular part, FusG: fusiform gyrus, MCgG: middle cingulate gyrus, MTG: middle temporal gyrus, SFG: superior frontal gyrus, SPG: superior parietal gyrus, CB: cerebellum lobule 8, ACC: anterior cingulate gyrus, MFG Orb: middle frontal gyrus orbital part. L: left, R: right.

Figure 4. Changes during the intervention vs. control period pooled across groups in 25 TBI patients. (A) VBM results from the intervention vs. control comparison (AB: TP2>TP1 \& BA: TP3>TP2 vs. AB: TP3>TP2 \& BA: TP2>TP1). The results are reported in MNI coordinates and at an uncorrected $p<0.001$ threshold at the voxel level. The right IFG Tri cluster shown survived a $p<0.05$ FWE-corrected threshold at the cluster level. (B) Bar plots (mean \pm SEM) for the number-letter task switching cost score (errors, \%) change (left) and the GMV change $\left(\mathrm{mm}^{3}\right)$ from the local maxima in the right IFG Tri cluster shown in (A) (right) during the intervention (INT) and control (CON) periods. (C) Pearson correlation between changes in the number-letter task switching 
cost (errors, \%) and in the GMV of the right IFG Tri cluster from (A) during the intervention period. IFG Tri:

inferior frontal gyrus triangular part, INS: insula, MOFC: medial orbitofrontal gyrus. R: right. 


\section{Enrollment}

Assessed for eligibility ( $n=4994)$

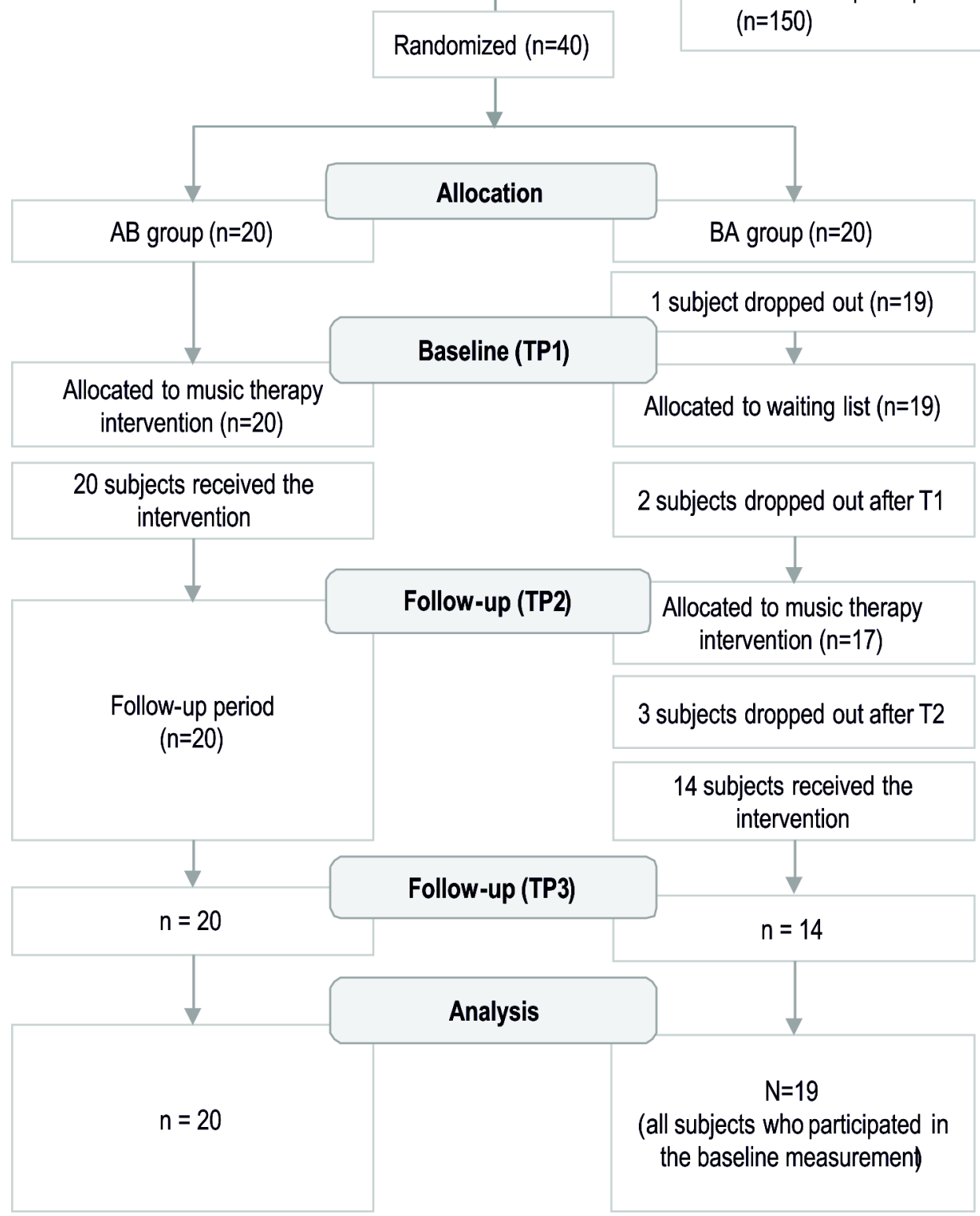

Excluded ( $\mathrm{n}=4954)$

- Not meeting inclusion criteria ( $n=4804$ )

- Declined to participate $(n=150)$

BA group $(n=20)$

1 subject dropped out $(n=19)$

Allocated to waiting list ( $\mathrm{n}=19)$

20 subjects received the intervention

2 subjects dropped out after T1

Allocated to music therapy intervention $(n=17)$

Follow-up period $(n=20)$ 

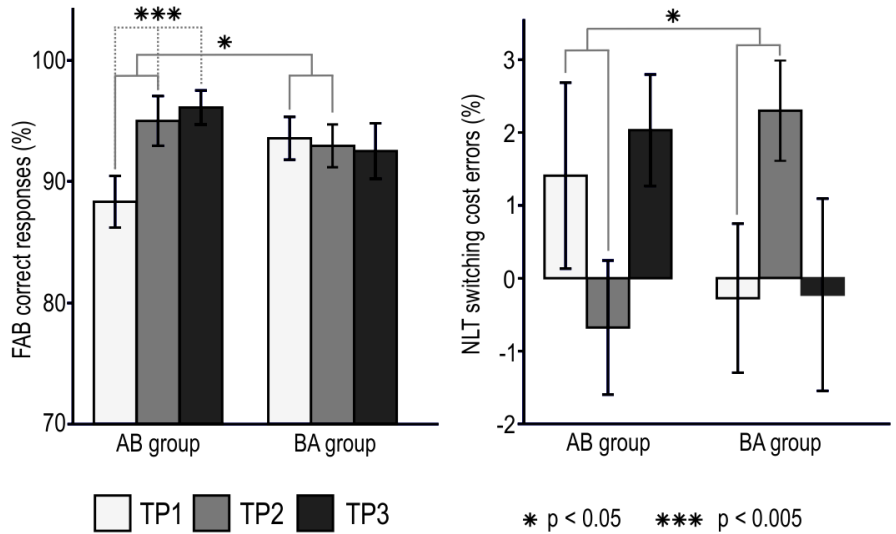

$* \mathrm{p}<0.05$ **** $\mathrm{p}<0.005$ 
A

$\mathrm{AB}>\mathrm{BA} \times \mathrm{TP2}>\mathrm{TP1}$

Mrest

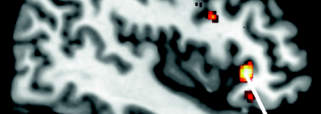

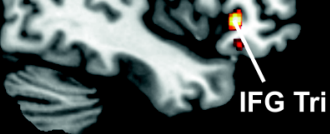

$\mathrm{R}$ $x=-49$

$L$

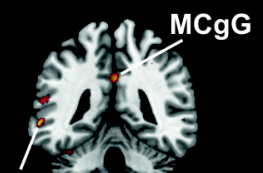

2.6

$x=44$ MTG

$y=-42$

R

D

IFG Tri R

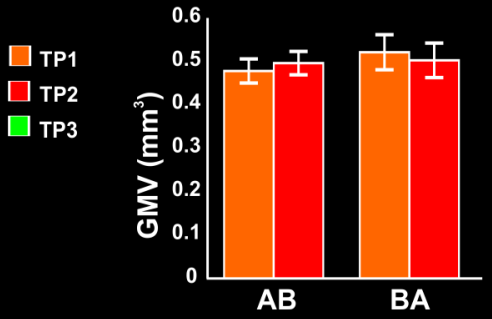

B

$\mathrm{BA}>\mathrm{AB} \times \mathrm{TP} 3>\mathrm{TP2}$
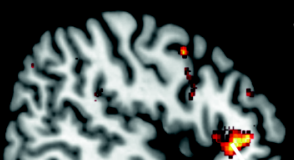

$\left(\frac{2 \pi}{4}\right)+5$ IFG Tri
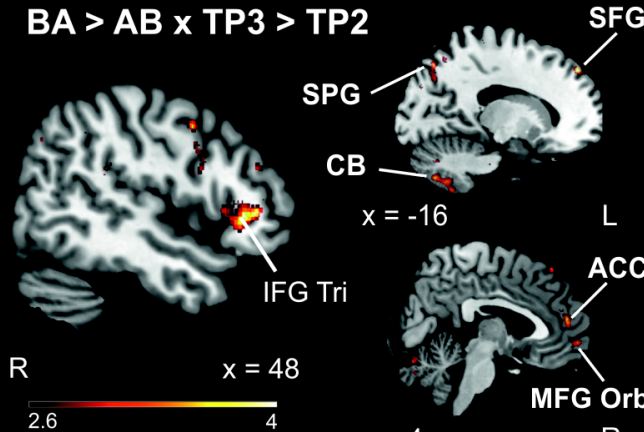

SFG

C

Conjunction

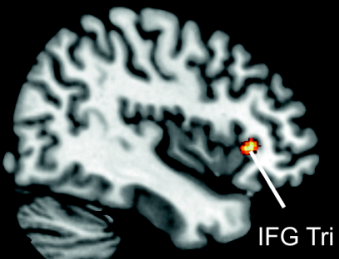

$\mathrm{R}$

MFG Orb

$\mathrm{x}=4$

$\mathrm{R}$

E

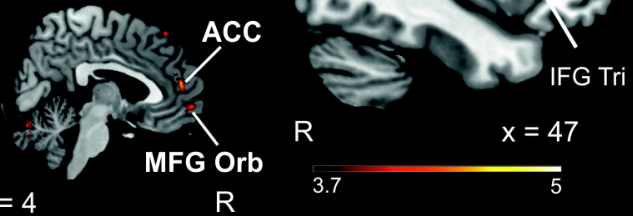

F

IFG Tri R

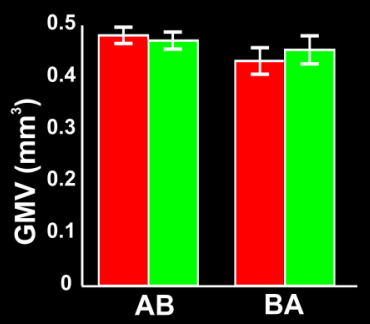

IFG Tri R

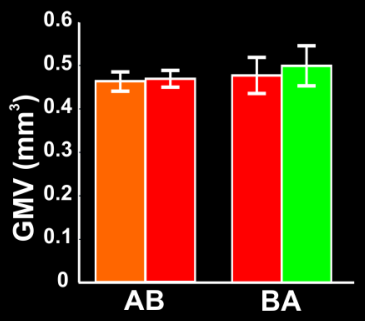



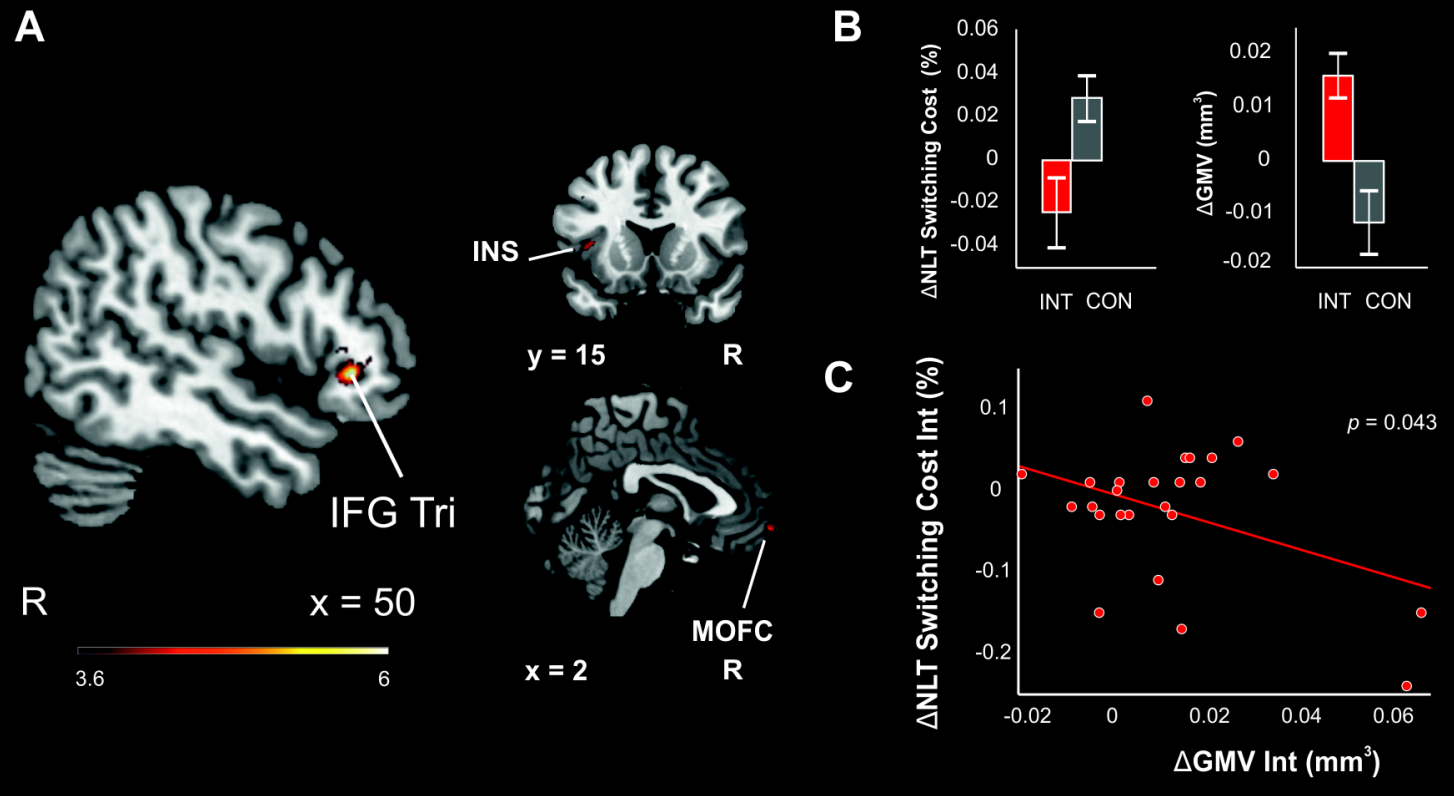
Table 1. Demographic, clinical and musical background information.

\begin{tabular}{|c|c|c|c|c|}
\hline & All & $A B$ & BA & $\begin{array}{l}\text { Difference between } \\
\text { groups }(p)\end{array}$ \\
\hline \multicolumn{5}{|c|}{ Demographic information } \\
\hline Age m (sd) & $41.3(13.3)$ & $41.6(14.7)$ & $40.9(12.0)$ & $.871(\mathrm{t})$ \\
\hline Gender (female / male) & $16 / 23$ & $10 / 10$ & $6 / 13$ & $.242\left(X^{2}\right)$ \\
\hline Handedness (right/left/both) & 37 / 1 / 1 & $19 / 0 / 1$ & $18 / 1 / 0$ & $1.000(F)$ \\
\hline Education in years $\mathrm{m}(\mathrm{sd})$ & $14.6(3.2)$ & $14.73(2.8)$ & $14.6(3.6)$ & $.867(\mathrm{t})$ \\
\hline \multicolumn{5}{|c|}{ Clinical information } \\
\hline GCS m (sd) & $11.8(4.2)$ & $12.3(3.6)$ & $11.2(4.7)$ & $.613(U)$ \\
\hline PTA classification ${ }^{\mathrm{a}} \mathrm{m}$ (sd) & $2.1(1.1)$ & $1.9(1.1)$ & $2.3(1.0)$ & $.280(\mathrm{t})$ \\
\hline $\begin{array}{l}\text { Cause of injury } \\
\text { (traffic-related / fall / other) }\end{array}$ & $16 / 15 / 8$ & $8 / 11 / 1$ & $8 / 4 / 7$ & $.022(\mathrm{~F})$ \\
\hline Time since injury (months) m (sd) & $8.9(6.4)$ & $8.6(6.7)$ & $9.2(6.3)$ & $.772(\mathrm{t})$ \\
\hline $\begin{array}{l}\text { Lesion lateralityb } \\
\text { (left / right / both) }\end{array}$ & $7 / 2 / 26$ & $4 / 1 / 14$ & $3 / 1 / 12$ & $1.0(F)$ \\
\hline Contusionc (yes / no) & $23 / 15$ & $13 / 6$ & $10 / 9$ & $.508\left(X^{2}\right)$ \\
\hline DAlc (yes / no) & $21 / 17$ & $9 / 10$ & $12 / 7$ & $.515\left(X^{2}\right)$ \\
\hline $\begin{array}{l}\text { Hemorrages, bleeds or ischemic } \\
\text { injuryc (yes / no) }\end{array}$ & $24 / 14$ & $10 / 9$ & $14 / 5$ & $.179\left(X^{2}\right)$ \\
\hline GOSEcm (sd) & $5.2(1.2)$ & $5.0(1.5)$ & $5.5(0.9)$ & $.192(\mathrm{t})$ \\
\hline NOS-TBId m (sd) & $2.0(2.5)$ & $2.2(2.4)$ & $1.8(2.7)$ & $.385(U)$ \\
\hline BDI-II m (sd) & $14.2(8.9)$ & $15.8(10.5)$ & $12.3(6.6)$ & $.229(\mathrm{t})$ \\
\hline \multicolumn{5}{|c|}{ Musical background } \\
\hline Instrument playing (yes / no) & $25 / 12$ & $14 / 6$ & $11 / 6$ & $.732\left(X^{2}\right)$ \\
\hline Years of playing m (sd) & $4.2(8.4)$ & $4.8(10.3)$ & $3.5(5.4)$ & $.613(U)$ \\
\hline Singing (yes / no) & $17 / 20$ & $11 / 9$ & $6 / 11$ & $.231\left(X^{2}\right)$ \\
\hline Years of singing $\mathrm{m}(\mathrm{sd})$ & $4.7(9.9)$ & $6.7(12.7)$ & $2.6(5.3)$ & $.369(U)$ \\
\hline Dancing (yes/no) & $20 / 17$ & $12 / 8$ & $7 / 10$ & $.254\left(X^{2}\right)$ \\
\hline Years of dancing $m(s d)$ & $6.1(10.8)$ & $6.3(10.6)$ & $5.8(11.4)$ & $.546(U)$ \\
\hline
\end{tabular}

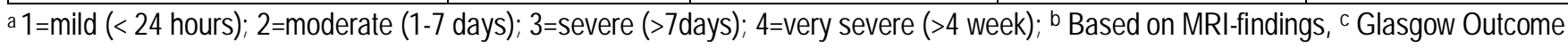
Scale Extended; d Neurological Outcome Scale for TBI 
Table 2. Amount of standard care rehabilitation in hours (60 min). In addition to traditional TBI therapies, four of the participants received some other therapy (e.g. psychotherapy), which were included in the overall sum of rehabilitation.

\begin{tabular}{|c|c|c|c|c|c|c|c|c|c|c|c|}
\hline & Group & $\begin{array}{c}\text { TP1 } \\
\text { m (sd) }\end{array}$ & $p$ & $\begin{array}{c}\text { TP2 } \\
\text { m (sd) }\end{array}$ & $p$ & $\begin{array}{c}\text { TP3 } \\
\text { m (sd) }\end{array}$ & $p$ & $\begin{array}{l}\text { Intervention } \\
\text { period } \\
m(s d)\end{array}$ & $p$ & $\begin{array}{l}\text { Control } \\
\text { period } \\
m(s d)\end{array}$ & $p$ \\
\hline \multirow[t]{2}{*}{ Physiotherapy } & $A B$ & $11.9(26.7)$ & \multirow{2}{*}{$.490(U)$} & $3.8(4.4)$ & \multirow{2}{*}{$.290(U)$} & $2.2(3.9)$ & \multirow{2}{*}{$.711(U)$} & $3.8(4.4)$ & \multirow{2}{*}{$.208(U)$} & $2.2(3.9)$ & \multirow{2}{*}{$.970(U)$} \\
\hline & BA & $16.3(29.0)$ & & $3.2(7.2)$ & & $1.7(3.9)$ & & $1.7(3.9)$ & & $3.2(7.2)$ & \\
\hline \multirow[t]{2}{*}{ Occupational therapy } & $A B$ & $5.2(17.2)$ & \multirow{2}{*}{$.589(U)$} & $2.2(5.1)$ & \multirow{2}{*}{$.873(U)$} & $0.5(1.7)$ & \multirow{2}{*}{$.711(U)$} & $1.7(3.8)$ & \multirow{2}{*}{$.906(U)$} & $0.5(1.7)$ & \multirow{2}{*}{$.720(U)$} \\
\hline & BA & $8.4(17.6)$ & & $2.1(6.9)$ & & $1.1(2.5)$ & & $1.1(2.5)$ & & $2.1(6.9)$ & \\
\hline \multirow{2}{*}{$\begin{array}{l}\text { Neuropsychological } \\
\text { rehabilitation }\end{array}$} & $A B$ & $11.4(19.7)$ & \multirow{2}{*}{$.452(U)$} & $2.5(3.8)$ & \multirow{2}{*}{$.896(U)$} & $3.0(3.2)$ & \multirow{2}{*}{$.187(U)$} & $2.5(3.8)$ & \multirow{2}{*}{$.332(U)$} & $3.0(3.2)$ & \multirow{2}{*}{$.799(U)$} \\
\hline & BA & $10.8(14.2)$ & & $2.9(3.8)$ & & $1.5(3.2)$ & & $1.5(3.2)$ & & $2.9(3.8)$ & \\
\hline \multirow[t]{2}{*}{ Speech therapy } & $A B$ & $4.4(17.2)$ & \multirow{2}{*}{$.502(U)$} & $0.8(2.3)$ & \multirow{2}{*}{$.837(U)$} & $0.4(1.6)$ & \multirow{2}{*}{$.824(U)$} & $0.8(2.3)$ & \multirow{2}{*}{$.654(U)$} & $0.4(1.6)$ & \multirow{2}{*}{$.681(U)$} \\
\hline & BA & $6.2(14.8)$ & & $3.2(8.4)$ & & $0.0(0.0)$ & & $0.0(0.0)$ & & $3.2(8.4)$ & \\
\hline \multirow[t]{2}{*}{ Sum } & $A B$ & 33.9 (78.2) & \multirow{2}{*}{$.415(U)$} & $9.3(12.4)$ & \multirow{2}{*}{$.630(U)$} & $6.2(8.3)$ & \multirow{2}{*}{$.334(U)$} & $9.3(12.4)$ & \multirow{2}{*}{$.226(U)$} & $6.2(8.3)$ & \multirow{2}{*}{$.911(U)$} \\
\hline & BA & $40.5(63.4)$ & & $11.0(22.7)$ & & $4.2(6.8)$ & & $4.2(6.8)$ & & $11.0(22.7)$ & \\
\hline
\end{tabular}


Table 3. Linear mixed model analysis (LMM) results between time points 1-2 using the complete dataset $(n=39)$, means and standard deviations are based on means of the imputed datasets. The indices represent Executive functiona (Frontal Assessment Battery), Reasoning ${ }^{\mathrm{b}}$ (WAIS-IV Similarities and Block Design), Verbal memoryc (WMS-III word lists and WAIS-IV digit span) and motor performanced (Box and block, ARAT, Purdue Peg Board) as the overall percentage of correct answers. SART vigilance decremente reflects the change in error percent over the lengthened 8.6 min task (error percent during $1^{\text {st }}$ half - error percent during $2^{\text {nd }}$ half); a positive number reflects decrease in errors towards the end and a negative number reflects an increase in errors. The baseline differences have been evaluated using independent samples t-test (t) or Mann Whitney U-test $(U)$.

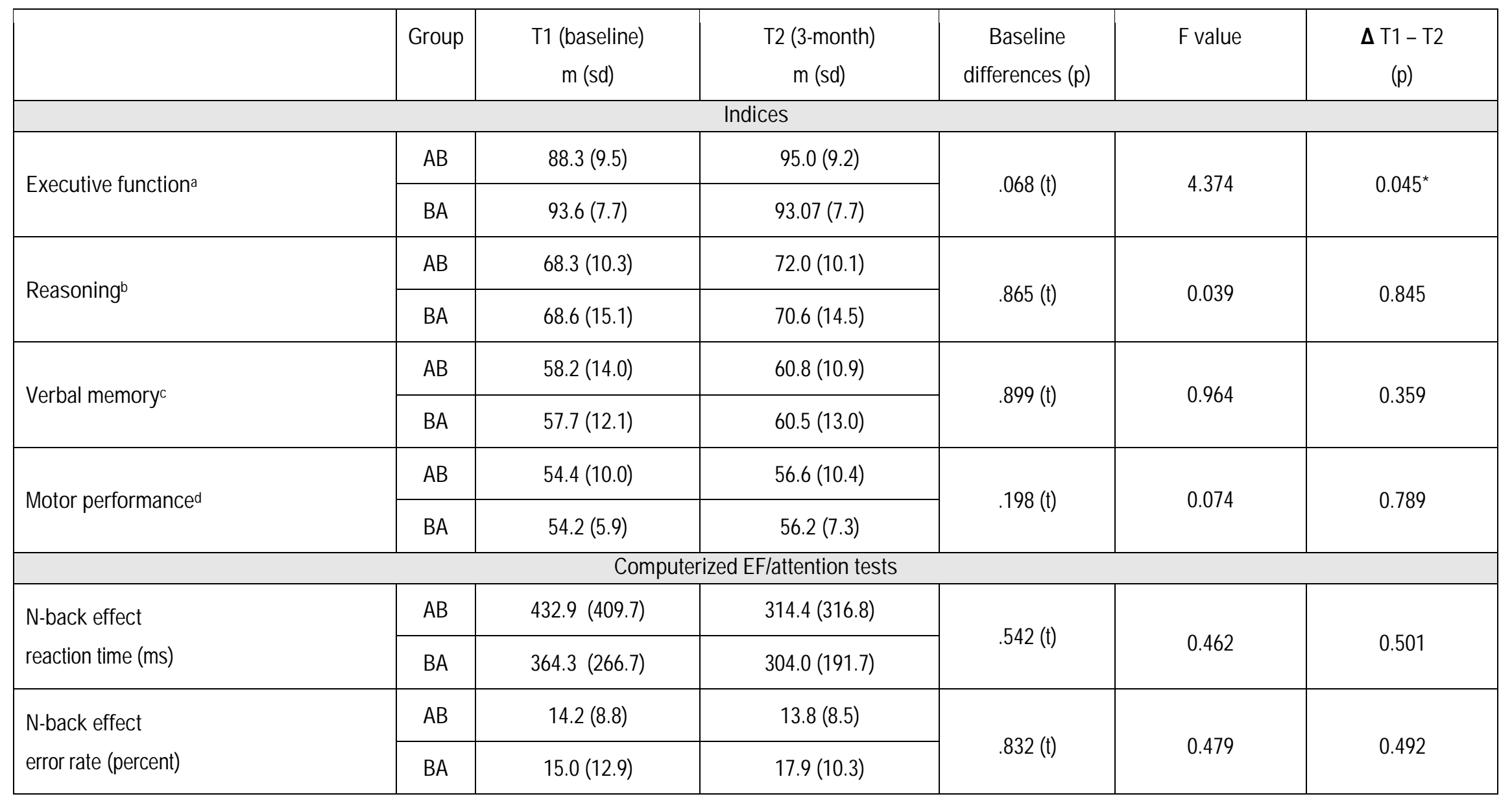




\begin{tabular}{|c|c|c|c|c|c|c|}
\hline \multirow{2}{*}{$\begin{array}{l}\text { NLT switching cost } \\
\text { reaction time (ms) }\end{array}$} & $A B$ & $379.3(273.5)$ & 443.7 (260.5) & \multirow{2}{*}{$.882(t)$} & \multirow{2}{*}{0.864} & \multirow{2}{*}{0.359} \\
\hline & BA & 390.2 (167.1) & $375.1(149.8)$ & & & \\
\hline \multirow{2}{*}{$\begin{array}{l}\text { NLT switching cost } \\
\text { error rate (percent) }\end{array}$} & $A B$ & $1.4(5.7)$ & $-0.7(4.1)$ & \multirow{2}{*}{$.314(\mathrm{t})$} & \multirow{2}{*}{4.798} & \multirow{2}{*}{$0.032^{*}$} \\
\hline & BA & $-0.3(4.5)$ & $2.3(3.0)$ & & & \\
\hline \multirow{2}{*}{$\begin{array}{l}\text { Simon effect } \\
\text { reaction time (ms) }\end{array}$} & $A B$ & $58.0(42.9)$ & $46.6(53.3)$ & \multirow{2}{*}{$.609(\mathrm{t})$} & \multirow{2}{*}{0.076} & \multirow{2}{*}{0.782} \\
\hline & BA & $63.8(26.0)$ & $56.8(40.1)$ & & & \\
\hline \multirow{2}{*}{$\begin{array}{l}\text { Simon effect } \\
\text { error rate (percent) }\end{array}$} & $A B$ & $0.5(1.3)$ & $1.8(2.5)$ & \multirow{2}{*}{$.068(t)$} & \multirow{2}{*}{1.895} & \multirow{2}{*}{0.182} \\
\hline & BA & $1.5(1.9)$ & $1.1(2.1)$ & & & \\
\hline \multirow{2}{*}{$\begin{array}{l}\text { SART } \\
\text { reaction time (ms) }\end{array}$} & $A B$ & $424.4(97.5)$ & $423.4(94.8)$ & \multirow{2}{*}{$.466(t)$} & \multirow{2}{*}{0.347} & \multirow{2}{*}{0.560} \\
\hline & BA & 399.9 (109.3) & $382.3(86.5)$ & & & \\
\hline \multirow{2}{*}{$\begin{array}{l}\text { SART } \\
\text { error and miss rate (percent) }\end{array}$} & $A B$ & $9.7(11.0)$ & $7.0(9.5)$ & \multirow{2}{*}{$.243(t)$} & \multirow{2}{*}{1.370} & \multirow{2}{*}{0.255} \\
\hline & BA & $6.6(3.9)$ & $6.1(4.5)$ & & & \\
\hline \multirow{2}{*}{$\begin{array}{l}\text { SART }^{\mathbf{e}} \\
\text { vigilance decrement (percent) }\end{array}$} & $A B$ & $-0.2(4.6)$ & $0.5(3.7)$ & \multirow{2}{*}{$.822(t)$} & \multirow{2}{*}{0.642} & \multirow{2}{*}{0.430} \\
\hline & BA & $-0.5(3.6)$ & $-0.9(3.0)$ & & & \\
\hline
\end{tabular}


Table 4. Whole-brain GM volume changes: (a) in the group (AB>BA) $x$ time (TP2>TP1) and (b) in the group $(B A>A B) x$ time (TP3>TP2) interactions and (c) the conjunction null between both interactions. Results are reported at $p<0.001$ unc threshold (extent threshold: $k=50$ voxels) using MNI coordinates.L: left, R: right.

a. $A B>B A \times T P 2>T P 1$

\begin{tabular}{|l|c|c|c|c|c|}
\hline Anatomical region & Cluster size & T value & $\mathbf{X}$ & $\mathbf{Y}$ & $\mathbf{Z}$ \\
\hline Fusiform L & 297 & 4.601 & -46 & -62 & -17 \\
\hline Frontal Inf Tri R & 393 & 4.401 & 44 & 28 & -1 \\
\hline Cerebelum 8 L & 185 & 4.120 & -31 & -59 & -49 \\
\hline Temporal Mid L & 53 & 4.003 & -62 & -42 & -3 \\
\hline Cingulum Mid L & 411 & 3.964 & 0 & -37 & 33 \\
\hline Frontal Mid R & 50 & 3.562 & 31 & 33 & 32 \\
\hline
\end{tabular}

b. $B A>A B \times T P 3>T P 2$

\begin{tabular}{|l|c|c|c|c|c|}
\hline Postcentral L & 147 & 4.506 & -64 & -5 & 20 \\
\hline Frontal Sup L & 79 & 4.328 & -16 & 47 & 44 \\
\hline Frontal Inf Tri R & 101 & 4.321 & 54 & 31 & 19 \\
\hline Frontal Med Orb R & 127 & 4.180 & 2 & 61 & -6 \\
\hline Frontal Inf Tri R & 305 & 4.150 & 48 & 35 & 1 \\
\hline Postcentral R & 94 & 4.125 & 27 & -27 & 62 \\
\hline Cerebellum 8 L & 201 & 4.092 & -25 & -67 & -47 \\
\hline Precentral R & 100 & 4.088 & 61 & 10 & 24 \\
\hline Postcentral R & 72 & 4.017 & 61 & -3 & 23 \\
\hline Frontal Mid R & 75 & 4.011 & 30 & 48 & 13 \\
\hline Frontal Inf Tri R & 109 & 3.913 & 55 & 22 & 9 \\
\hline Cerebelum 8 L & 139 & 3.879 & -13 & -71 & -45 \\
\hline Parietal Sup L & 104 & 3.823 & -14 & -74 & 47 \\
\hline Cingulum Ant R & 81 & 3.809 & 4 & 50 & 14 \\
\hline Occipital Inf L & 58 & 3.790 & -45 & -77 & -6 \\
\hline Fusiform L & 52 & 3.775 & -36 & -16 & -33 \\
\hline Frontal Inf Orb L & 52 & 3.732 & -37 & 33 & -14 \\
\hline \multicolumn{2}{|c|}{ Conjunction null (AB>BA x TP2>TP1 \& BA>AB x TP3>TP2) } & \\
\hline Frontal Inf Tri R & 152 & 3.903 & 47 & 29 & -2 \\
\hline
\end{tabular}


Table 5. Whole-brain effects on GM volume pooling data from $A B$ and $B A$ groups: (a) intervention period only test (AB: TP2>TP1 \& BA: TP3>TP2) and (b) intervention > control period (AB: TP2>TP1 \& BA: TP3>TP2 vs. AB: TP3 $>$ TP2 \& BA: TP2>TP1). Results are reported at $p<0.001$ unc threshold (extent threshold: $k=50$ voxels) using MNI coordinates. Asterisk $\left.{ }^{\star \star}\right)$ denotes $p<0.05$ FWE-corrected at cluster level. L: left, R: right.

\section{a. Intervention period only}

\begin{tabular}{|l|c|c|c|c|c|}
\hline Anatomical region & Cluster size & T value & $\mathbf{X}$ & $\mathbf{Y}$ & $\mathbf{Z}$ \\
\hline Frontal Inf Tri $\mathbf{R}^{\star \star}$ & 916 & 5.041 & 50 & 30 & 0 \\
\hline Hippocampus R & 66 & 5.005 & 28 & -16 & -16 \\
\hline Frontal Sup R & 76 & 4.444 & 24 & 36 & 38 \\
\hline Frontal Inf Oper R & 67 & 4.327 & 45 & 11 & 25 \\
\hline Frontal Inf Tri R & 50 & 4.200 & 54 & 22 & 12 \\
\hline
\end{tabular}

b. Intervention $>$ Control period

\begin{tabular}{|l|c|c|c|c|c|}
\hline Frontal Inf Tri $\mathbf{R}^{* *}$ & 652 & 6.898 & 50 & 30 & -1 \\
\hline Temporal Inf L & 280 & 4.830 & -48 & -68 & -6 \\
\hline Occipital Inf L & 208 & 4.644 & -48 & -63 & -16 \\
\hline Frontal Med Orb L & 92 & 4.540 & 2 & 57 & -10 \\
\hline Insula L & 216 & 4.472 & -39 & 15 & 7 \\
\hline Cerebelum 8 L & 198 & 4.305 & -12 & -70 & -45 \\
\hline Cerebelum Crus1 L & 126 & 4.293 & -21 & -66 & -33 \\
\hline Temporal Mid L & 51 & 4.240 & -56 & -59 & 8 \\
\hline Cingulum Post L & 89 & 4.193 & -1 & -38 & 30 \\
\hline Frontal Mid R & 55 & 4.097 & 40 & 20 & 36 \\
\hline Front Inf Orb L & 51 & 3.985 & -37 & 31 & -12 \\
\hline
\end{tabular}


Supplemental table 1. Demographic, clinical and musical background information for the per protocol sample $(n=25)$.

\begin{tabular}{|c|c|c|c|c|}
\hline & All & $A B$ & BA & $\begin{array}{c}\text { Difference } \\
\text { between groups } \\
(\mathrm{p})\end{array}$ \\
\hline \multicolumn{5}{|c|}{ Demographic information } \\
\hline Age & $41.6(13.3)$ & $42.1(14.6)$ & $40.8(11.5)$ & $.814(\mathrm{t})$ \\
\hline Gender (female / male) & $10 / 15$ & $7 / 9$ & $3 / 6$ & $.470(\mathrm{~F})$ \\
\hline Handedness (right/left/both) & $23 / 1 / 1$ & $15 / 0 / 1$ & $8 / 1 / 0$ & $.600(F)$ \\
\hline Education in years $\mathrm{m}(\mathrm{sd})$ & $14.5(2.5)$ & $14.3(2.7)$ & $14.9(2.1)$ & $.535(\mathrm{t})$ \\
\hline \multicolumn{5}{|c|}{ Clinical information } \\
\hline GCS m (sd) & $12.7(3.5)$ & $12.9(3.5)$ & $12.4(3.8)$ & $.664(U)$ \\
\hline PTA classification ${ }^{\mathrm{a}} \mathrm{m}(\mathrm{sd})$ & $1.7(1.0)$ & $1.6(1.1)$ & $1.9(0.8)$ & $.607(\mathrm{t})$ \\
\hline $\begin{array}{l}\text { Cause of injury } \\
\text { (traffic-related / fall / other) }\end{array}$ & $8 / 12 / 5$ & $6 / 9 / 1$ & $2 / 3 / 4$ & $.09(\mathrm{~F})$ \\
\hline Time since injury (months) & $7.9(6.0)$ & $8.4(6.0)$ & $7.1(6.1)$ & $.622(\mathrm{t})$ \\
\hline $\begin{array}{l}\text { Lesion laterality } \\
\text { (left / right / both) }\end{array}$ & $6 / 1 / 17$ & $3 / 1 / 11$ & $3 / 0 / 6$ & $.777(\mathrm{~F})$ \\
\hline Contusionc (yes / no) & $12 / 12$ & $10 / 5$ & $2 / 7$ & $.045^{*}(\mathrm{~F})$ \\
\hline $\mathrm{DAl}^{\mathrm{c}}$ (yes / no) & $12 / 12$ & $6 / 9$ & $6 / 3$ & $.400(\mathrm{~F})$ \\
\hline $\begin{array}{l}\text { Hemorrages, bleeds or } \\
\text { ischemic injuryc (yes / no) }\end{array}$ & $15 / 9$ & $10 / 5$ & $5 / 4$ & $.678(\mathrm{~F})$ \\
\hline GOSEc $^{c}$ (sd) & $5.3(1.3)$ & $5.2(1.5)$ & $5.6(1.1)$ & $.541(\mathrm{t})$ \\
\hline NOS-TBId m (sd) & $1.9(2.1)$ & $2.0(2.1)$ & $1.8(2.3)$ & $.812(\mathrm{t})$ \\
\hline \multicolumn{5}{|c|}{ Musical background } \\
\hline Instrument playing (yes / no) & $17 / 8$ & $11 / 5$ & $6 / 3$ & $.1 .00(\mathrm{~F})$ \\
\hline Years of playing $\mathrm{m}(\mathrm{sd})$ & $4.8(9.9)$ & $5.1(11.3)$ & $3.8(2.4)$ & $.850(U)$ \\
\hline Singing (yes / no) & $12 / 13$ & $9 / 7$ & $3 / 6$ & $.411(\mathrm{~F})$ \\
\hline Years of singing $\mathrm{m}(\mathrm{sd})$ & $5.5(11.3)$ & $7.9(13.7)$ & $1.3(3.0)$ & $.215(U)$ \\
\hline Dancing (yes/no) & $13 / 12$ & $9 / 7$ & $4 / 5$ & $.688(\mathrm{~F})$ \\
\hline Years of dancing $\mathrm{m}(\mathrm{sd})$ & $5.2(10.2)$ & $5.4(10.9)$ & $4.8(9.8)$ & $.815(U)$ \\
\hline
\end{tabular}

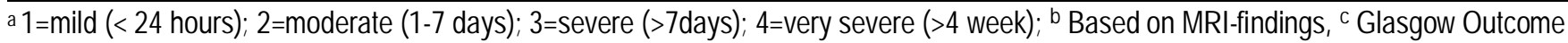

Scale Extended; d Neurological Outcome Scale for TBI 
Supplemental table 2. Amount of standard care rehabilitation in hours (60 min) received by the per protocol sample $(n=25)$.

\begin{tabular}{|c|c|c|c|c|c|c|c|c|c|c|c|}
\hline & Group & $\begin{array}{c}\text { T1 } \\
\mathrm{m}(\mathrm{sd})\end{array}$ & $p$ & $\begin{array}{c}\text { T2 } \\
\mathrm{m}(\mathrm{sd})\end{array}$ & $p$ & $\begin{array}{c}\text { T3 } \\
\mathrm{m}(\mathrm{sd})\end{array}$ & $p$ & $\begin{array}{c}\text { Intervention } \\
\text { period } \\
\text { m (sd) }\end{array}$ & $p$ & $\begin{array}{l}\text { Control } \\
\text { period } \\
\mathrm{m}(\mathrm{sd})\end{array}$ & $p$ \\
\hline \multirow[t]{2}{*}{ Physiotherapy } & $A B$ & $6.3(12.3)$ & \multirow{2}{*}{$.728(U)$} & $3.4(4.3)$ & \multirow{2}{*}{$.392(U)$} & $2.0(3.9)$ & \multirow{2}{*}{$.841(U)$} & $3.4(4.3)$ & \multirow{2}{*}{$.677(U)$} & $2.0(3.9)$ & \multirow{2}{*}{$.920(U)$} \\
\hline & $B A$ & $9.9(16.6)$ & & $1.7(3.3)$ & & $2.8(4.9)$ & & $2.7(4.9)$ & & $1.7(3.3)$ & \\
\hline \multirow[t]{2}{*}{ Occupational therapy } & $A B$ & $1.6(3.6)$ & \multirow{2}{*}{$.875(U)$} & $1.3(3.2)$ & \multirow{2}{*}{$.728(U)$} & $0.2(0.6)$ & \multirow{2}{*}{$.718(U)$} & $1.3(3.2)$ & \multirow{2}{*}{$.910(U)$} & $0.2(0.6)$ & \multirow{2}{*}{$.868(U)$} \\
\hline & $\mathrm{BA}$ & $5.6(15.9)$ & & $0.3(0.8)$ & & $0.5(1.2)$ & & $0.5(1.2)$ & & $0.3(0.8)$ & \\
\hline \multirow{2}{*}{$\begin{array}{l}\text { Neuropsychological } \\
\text { rehabilitation }\end{array}$} & $A B$ & $8.5(13.5)$ & \multirow{2}{*}{$.975(U)$} & $1.4(2.2)$ & \multirow{2}{*}{$.728(U)$} & $2.7(2.9)$ & \multirow{2}{*}{$.274(U)$} & $1.4(2.2)$ & \multirow{2}{*}{$.569(U)$} & $2.7(2.9)$ & \multirow{2}{*}{$.764(U)$} \\
\hline & BA & $8.3(11.7)$ & & $2.5(3.8)$ & & $1.3(3.1)$ & & $1.3(3.1)$ & & $2.5(3.8)$ & \\
\hline \multirow[t]{2}{*}{ Speech therapy } & $A B$ & $0.6(2.3)$ & \multirow{2}{*}{$.825(U)$} & $0.3(1.2)$ & \multirow{2}{*}{$.825(U)$} & $0.0(0.0)$ & \multirow{2}{*}{$1.0(U)$} & $0.3(1.2)$ & \multirow{2}{*}{$.850(U)$} & $0.0(0.0)$ & \multirow{2}{*}{$.664(U)$} \\
\hline & $\mathrm{BA}$ & $1.5(4.2)$ & & $2.3(6.4)$ & & $0.0(0.0)$ & & $0.0(0.0)$ & & $2.3(6.4)$ & \\
\hline \multirow[t]{2}{*}{ Sum } & $A B$ & $18.2(29.8)$ & \multirow{2}{*}{$.776(U)$} & $7.0(9.4)$ & \multirow{2}{*}{$.975(U)$} & $5.1(5.5)$ & \multirow{2}{*}{$.602(U)$} & $7.0(9.4)$ & \multirow{2}{*}{$.569(U)$} & $5.1(5.5)$ & \multirow{2}{*}{$.973(U)$} \\
\hline & $\mathrm{BA}$ & $24.5(32.9)$ & & $6.7(9.6)$ & & $4.5(7.0)$ & & $4.5(7.0)$ & & $6.7(9.6)$ & \\
\hline
\end{tabular}


Supplemental Table 3. Linear mixed-model ANOVA results between time points 1-2 using the per protocol sample ( $\mathrm{n}=25)$. The baseline differences have been evaluated using independent samples t-test $(\mathrm{t})$ or Mann Whitney U-test $(\mathrm{U})$.

\begin{tabular}{|c|c|c|c|c|c|}
\hline & Group & Tp1 (baseline) & Tp2 (3-month) & Baseline differences & $\begin{array}{c}\Delta \mathrm{T} 1-\mathrm{T} 2 \\
(\mathrm{p})\end{array}$ \\
\hline \multicolumn{6}{|c|}{ Indices } \\
\hline \multirow{2}{*}{$\begin{array}{l}\text { Executive function }{ }^{\mathrm{a}} \\
\mathrm{m}(\mathrm{sd})\end{array}$} & $A B$ & $88.2(10.1)$ & $97.2(4.5)$ & \multirow{2}{*}{$.060(\mathrm{t})$} & \multirow{2}{*}{$.024^{*}$} \\
\hline & $\mathrm{BA}$ & $95.7(6.7)$ & $95.7(7.2)$ & & \\
\hline \multirow{2}{*}{$\begin{array}{l}\text { Reasoning } \\
\mathrm{m}(\mathrm{sd})\end{array}$} & $A B$ & $70.5(10.4)$ & $72.7(10.3)$ & \multirow{2}{*}{$.635(\mathrm{t})$} & \multirow{2}{*}{.769} \\
\hline & BA & $72.7(10.3)$ & $75.7(12.7)$ & & \\
\hline \multirow{2}{*}{$\begin{array}{l}\text { Verbal memoryc } \\
\mathrm{m}(\mathrm{sd})\end{array}$} & $A B$ & $60.6(10.8)$ & $62.3(10.1)$ & \multirow{2}{*}{$.586(\mathrm{t})$} & \multirow{2}{*}{.428} \\
\hline & $\mathrm{BA}$ & $58.3(8.5)$ & $63.1(9.4)$ & & \\
\hline \multirow{2}{*}{$\begin{array}{l}\text { Motor performance } \\
\text { m (sd) }\end{array}$} & $A B$ & $52.3(8.8)$ & $54.0(9.3)$ & \multirow{2}{*}{$.535(\mathrm{t})$} & \multirow{2}{*}{.384} \\
\hline & BA & $54.4(6.7)$ & $57.2(8.5)$ & & \\
\hline \multicolumn{6}{|c|}{ Computerized EFlattention tests } \\
\hline \multirow{2}{*}{$\begin{array}{l}\text { N-back effect reaction time (ms) } \\
m(s d)\end{array}$} & $A B$ & $503.3(376.5)$ & $349.1(328.4)$ & \multirow{2}{*}{$.633(\mathrm{t})$} & \multirow{2}{*}{.973} \\
\hline & $\mathrm{BA}$ & $450.0(170.9)$ & $299.9(189.6)$ & & \\
\hline \multirow{2}{*}{$\begin{array}{l}\text { N-back effect error rate (percent) } \\
m(s d)\end{array}$} & $A B$ & $14.9(9.3)$ & $14.6(8.6)$ & \multirow{2}{*}{$.737(\mathrm{t})$} & \multirow{2}{*}{.629} \\
\hline & $\mathrm{BA}$ & $13.3(13.3)$ & $16.0(9.7)$ & & \\
\hline \multirow{2}{*}{$\begin{array}{l}\text { NLT switching cost reaction time (ms) } \\
\mathrm{m}(\mathrm{sd})\end{array}$} & $A B$ & $405.5(240.9)$ & $472.4(256.2)$ & \multirow{2}{*}{$.836(t)$} & \multirow{2}{*}{.605} \\
\hline & $\mathrm{BA}$ & $386.3(174.0)$ & $384.6(208.7)$ & & \\
\hline \multirow{2}{*}{$\begin{array}{l}\text { NLT switching cost error rate (percent) } \\
\text { m (sd) }\end{array}$} & $A B$ & $1.2(6.4)$ & $-0.9(4.4)$ & \multirow{2}{*}{$.411(\mathrm{t})$} & \multirow{2}{*}{.090} \\
\hline & $\mathrm{BA}$ & $-0.8(4.1)$ & $2.4(1.9)$ & & \\
\hline \multirow{2}{*}{$\begin{array}{l}\text { Simon effect reaction time }(\mathrm{ms}) \\
\mathrm{m}(\mathrm{sd})\end{array}$} & $A B$ & $57.6(47.5)$ & $42.1(57.1)$ & \multirow{2}{*}{$.889(\mathrm{t})$} & \multirow{2}{*}{.760} \\
\hline & $\mathrm{BA}$ & $59.6(21.5)$ & $37.3(39.2)$ & & \\
\hline \multirow{2}{*}{$\begin{array}{l}\text { Simon effect error rate (percent) } \\
m(s d)\end{array}$} & $A B$ & $2.5(1.0)$ & $1.6(1.7)$ & \multirow{2}{*}{$.043^{*}(t)$} & \multirow{2}{*}{$.001^{*}$} \\
\hline & $\mathrm{BA}$ & $1.8(1.9)$ & $0.2(0.7)$ & & \\
\hline SART reaction time (ms) & $A B$ & $409.4(80.2)$ & $410.5(92.1)$ & & \\
\hline m (sd) & BA & $366.4(65.5)$ & $372.6(107.9)$ & $.184(\mathrm{t})$ & .891 \\
\hline SART error and miss rate (percent) & $A B$ & $9.6(11.2)$ & $7.1(10.1)$ & 200 & 555 \\
\hline m (sd) & $\mathrm{BA}$ & $6.2(3.8)$ & $4.8(3.4)$ & $.389(1)$ & .050 \\
\hline SART $^{\mathrm{e}}$ vigilance decrement (percent) & $A B$ & $0.1(4.1)$ & $1.3(3.6)$ & $367(t)$ & 328 \\
\hline $\mathrm{m}(\mathrm{sd})$ & BA & $-0.6(3.9)$ & $-1.5(1.4)$ & .007 (L) & $.0 \angle 0$ \\
\hline
\end{tabular}

